\title{
TISSUE REACTIONS TO ASPERGILLUS IN CASES OF HODGKIN'S DISEASE AND LEUKAEMIA
}

BY

\author{
N. F. C. GOWING AND IRIS M. E. HAMLIN \\ From the Department of Morbid Anatomy, Royal Marsden Hospital, London
}

(RECEIVED FOR PUBLICATION MARCH 24, 1960)

Five cases of aspergillosis complicating Hodgkin's disease and leukaemia are reported. The organs involved were: lungs (all five cases), stomach (Case 3); brain and meninges (Case 4); heart, kidneys, spleen, thyroid, and liver (Case 2). Cultures of Aspergillus fumigatus were obtained from the post-mortem tissues of three patients.

All the lesions in Case 2 were suppurative. The other four cases had non-suppurative lesions characterized by spreading coagulation necrosis with peripheral hyperaemia, exudation, and haemorrhage. Invasion and occlusion of blood vessels occurred frequently.

The various factors that may be responsible for the initiation and progression of the fungal infection are discussed. The available evidence suggests that Aspergillus fumigatus can produce toxic metabolites which are able to cause tissue necrosis and vascular damage. In patients suffering from neoplastic conditions of the lympho-reticular system, especially if steroid hormones or radiomimetic drugs are given, spreading, necrotizing lesions can develop unchecked by antibody or cellular defences.

During recent years deep (systemic) fungal infections have assumed considerable importance. The increasing use of powerful antibiotics, various chemotherapeutic agents, and steroid hormones has coincided with a rising incidence of mycoses complicating other diseases, especially neoplastic conditions of the lympho-reticular system. Before these drugs were introduced, aspergillosis usually presented as a chronic bronchopulmonary disease. In a classical monograph, Rénon (1897) described it as an occupational hazard amongst pigeonfeeders and wig-makers. Coe (1945) reported the case of a man aged 47 who had worked for 20 years in the Union Stock Yards. He noted that aspergillus is a regular inhabitant of the soil and can be isolated frequently from cereal products, unmilled grain, hay, and other stock foods. The organism was saprophytic on the grain and cornmeal used by these workers. Aspergillosis may also complicate other chronic pulmonary diseases such as carcinoma, lung abscess, tuberculosis, pneumoconiosis, and bronchiectasis (Heppleston and Gloyne, 1949 ; Hinson, Moon, and Plummer, 1952 ; Golebiowski, 1958 ; Finegold, Will, and Murray, 1959). When aspergillosis complicates a generalized debilitating disease such as malignant lymphoma treated with one or more of the various drugs now in use, the fungal infection is more rapidly progressive and has an increased tendency to disseminate.
The purpose of this paper is to record five additional cases of aspergillosis complicatin leukaemia and Hodgkin's disease. In particula we wish to describe in some detail the tissue reactions to the fungus in this type of case. We do not propose to review the historical or myco- $\stackrel{\mathbb{Q}}{\circ}$ logical aspects since these have been adequately $\overrightarrow{\vec{A}}$ covered by other workers (Hinson et al., 1952; Thom and Raper, 1945).

\section{Material and Methods}

During a period of 18 months (November, 1957, 응 to May, 1959) aspergillosis was discovered post $\frac{\sigma}{3}$ mortem in five patients at the Royal Marsden Hospital. The primary disease was Hodgkin's lymphoma $\delta$ in one case, acute myeloid leukaemia in three, and $₹$ lymphatic leukaemia in one (Table I). Over the 0 same period, 65 necropsies were performed on patients with leukaemia or malignant lymphoma, so $\frac{7}{2}$ that the proportion showing secondary aspergillus infection was between 7 and $8 \%$. In no case was N the diagnosis of aspergillosis made during life. Aspergillus fumigatus was isolated from post-mortem 0 tissues in three patients (Cases 1,2, and 5): swabs $\mathrm{N}_{\mathrm{W}}$ were taken from the lesions and inoculated on to 0 Sabouraud's medium, subculturing being continued until a pure growth was procured (Fig. 1). In the other two cases, cultures were not obtained, but we feel that there is little doubt that the organism seen? in tissue sections was an aspergillus since morpho- 0 logical criteria were satisfied (Torack, 1957); the hyphae were of medium width $(10-15 \mu)$, were septate, $\stackrel{D}{\varrho}$ 
TABLE I

SUMMARY OF PRESENT SERIES

\begin{tabular}{|c|c|c|c|c|c|c|}
\hline $\begin{array}{c}\text { Case No. and } \\
\text { Laboratory } \\
\text { Reference }\end{array}$ & Sex & Age & $\begin{array}{c}\text { Pre- } \\
\text { disposing } \\
\text { Disease }\end{array}$ & $\begin{array}{c}\text { Type of Tissue } \\
\text { Response to } \\
\text { Aspergillus }\end{array}$ & Organs Involved & Other Infections \\
\hline $\begin{array}{l}\text { PM. } 108 / 57 \\
\text { PM. }{ }^{2} 57 / 58 \\
3_{i}^{3} \\
\text { PM. }{ }^{83 / 58} \\
\text { PM. }{ }^{5 / 59} \\
\text { PM. } 32 / 59\end{array}$ & $\begin{array}{l}\mathbf{F} \\
\mathbf{M} \\
\mathbf{M} \\
\mathbf{F} \\
\mathbf{M}\end{array}$ & $\begin{array}{l}41 \\
44 \\
32 \\
14 \\
40\end{array}$ & $\begin{array}{l}\text { Hodgkin's } \\
\text { disease } \\
\text { Acute myeloid } \\
\text { leukaemia } \\
\text { Acute lymphatic } \\
\text { leukaemia } \\
\text { Acute myeloid } \\
\text { leukaemia } \\
\text {,, ", }\end{array}$ & $\begin{array}{l}\text { Spreading, } \\
\text { necrotizing } \\
\text { Suppurative } \\
\text { Spreading, } \\
\text { necrotizing } \\
\text { Spreading, } \\
\text { necrotizing } \\
\text {,, }\end{array}$ & $\begin{array}{l}\text { Lungs } \\
\text { Lungs, liver, kidneys, spleen, myo- } \\
\text { cardium, pericardium, thyroid } \\
\text { Tracheal mucosa, lungs, pharynx, } \\
\text { stomach } \\
\text { Lungs, brain, meninges } \\
\text { Lungs }\end{array}$ & $\begin{array}{l}\text { Staphylococcal abscesses of lung; } \\
\text { staphylococcal empyema; moni- } \\
\text { liasis pharynx and oesophagus } \\
\text { - } \\
\text { Small staphylococcal abscesses in } \\
\text { skin and myocardium }\end{array}$ \\
\hline
\end{tabular}

and showed prominent branching (Fig. 2). Typical sporing heads were found in sections prepared from the lungs of Case 1 (Fig. 3). Multiple tissue blocks were fixed in $10 \%$ buffered formalin and embedded in paraffin wax in the usual way. Sections were stained by the following methods: haematoxylin and eosin, Weigert's iron haematoxylin and van Gieson's mixture, Weigert's elastin stain, Mallory's phosphotungstic-acid-haematoxylin, the picro-Mallory and acid picro-Mallory techniques (Lendrum, 1949), silver impregnation for reticulin, the periodic-acid-Schiff technique, Gram's method, Perls' reaction for iron, and toluidine blue and alcian blue (for acid mucopolysaccharides). In addition, it was found that staining with carbol fuchsin and counterstaining with light green was a very satisfactory technique for the differential colouring of hyphae and spores.

\section{Clinical Features}

Details of treatment and white cell counts are summarized in Figs. 4 to 8 . The following are brief résumés of the individual case records.

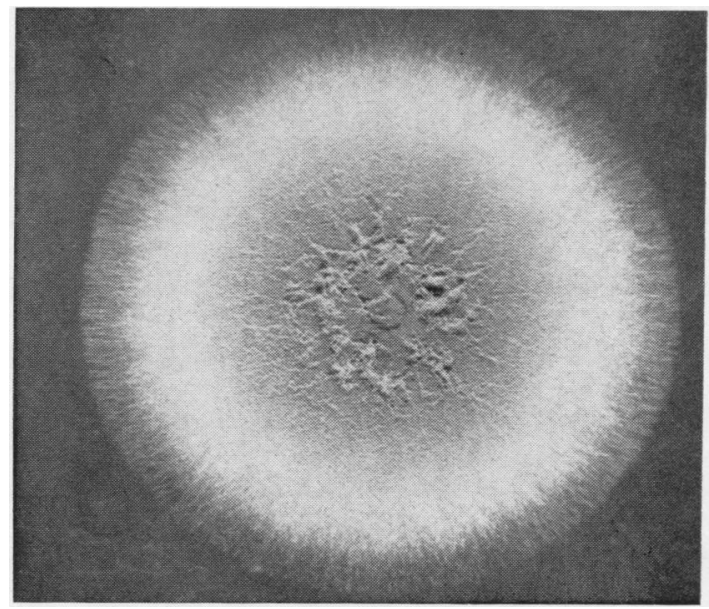

FIG. 1.-Pure culture of Aspergillus fumigatus isolated from Case 5. $2 I^{*}$
Case 1.-A woman aged 41 years first noticed enlarged cervical lymph nodes in December, 1956. Biopsy in February, 1957, showed typical Hodgkin's disease. In March, block dissection of the cervical nodes was carried out. Radiotherapy to the mediastinum, neck, and left axilla was given in May. She remained very well until November, when she was readmitted to hospital on November 6, 1957, with a three weeks' history of fever and malaise. For a few days she was treated with aminochlorambucil without effect. Prednisolone, penicillin, and streptomycin likewise produced no improvement. Her respiration and pulse rates rose and remained high until her death on November 20, 1957.

Case 2.-A man aged 44 years was apparently in good health until Christmas, 1957, when symptoms of increasing fatigue, dyspnoea, and headaches began. A diagnosis of acute myeloid leukaemia was established, and he was treated with 6-mercaptopurine, prednisolone, and blood transfusions. His general condition remained fair until May 2, 1958, when he was readmitted with dyspnoea, cough, foul sputum, muscular tenderness, and severe general malaise. Examination showed some rales at both bases and generalized muscle tenderness. His condition deteriorated rapidly with increasing dyspnoea, pyrexia, and tachycardia until his death on May 6 , 1958.

Case 3.-A man aged 32 years had complained of tiredness and dyspnoea for a few months. Investigations established the diagnosis of lymphatic leukaemia in May, 1957. At this time the spleen was palpable and there were enlarged lymph nodes in the neck and mediastinum. Treatment with 6-mercaptopurine and blood transfusions produced considerable improvement. Later in 1957 he was given methotrexate and prednisolone. Aminochlorambucil was administered in April, 1958, after his blood count was found to be rising again. During May and June further blood transfusions were needed. In July he became acutely ill with pain in the left chest, productive cough with blood-stained sputum, and purpura of the skin. His condition deteriorated rapidly, and he died on July 12, 1958. 


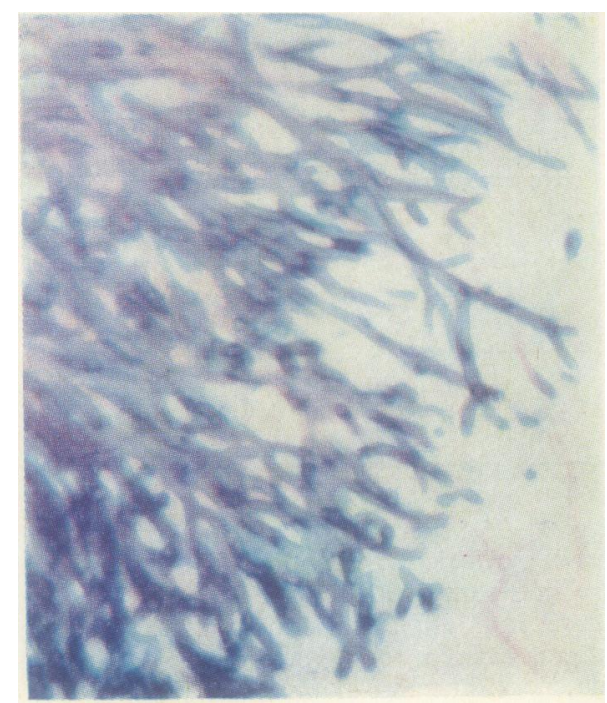

FIG. 2

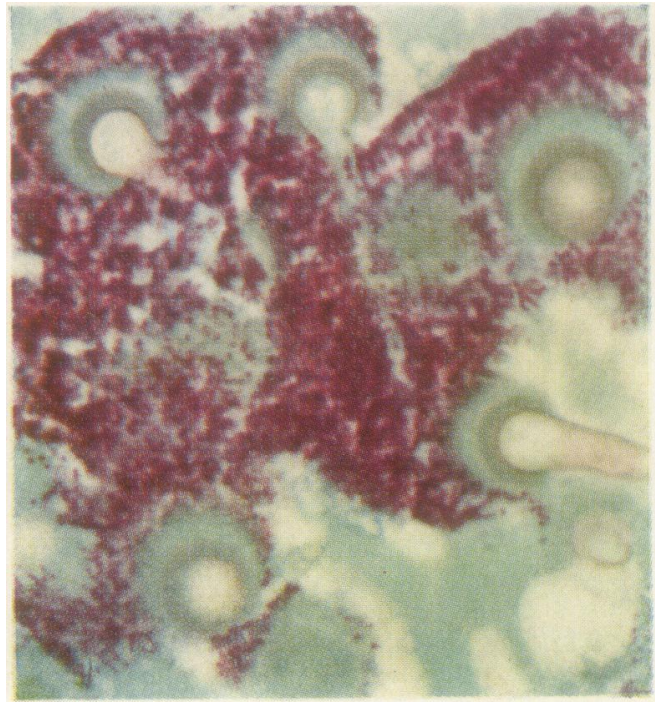

FIO. 3

Fig. 2.-Case 1. Fungal hyphas in a section of the right lung. Haematoxylin and eosin $\times 320$.

FIG. 3. Case 1. Sporing heads of Aspergillus fumigatus in a bronchial lumen. Prepared from the same tissue block as the section illustrated in Fig. 14. Spores red: hyphae, vesicles, and sterigmata green. Carbol fuchsin, light green $\times 320$.

Case 4.-A schoolgirl aged 14 years presented with fatigue, pyrexia, a papular rash, enlarged glands in both axillae, splenomegaly, and hepatomegaly. A diagnosis of acute myeloid leukaemia was established in December, 1957. She was treated with prednisolone and 6-mercaptopurine. This produced a remission that lasted until July, 1958, when symptoms recurred. Further treatment with 6-mercaptopurine produced haematological improvement, but she still felt unwell. In December, 1958, she was readmitted to hospital in a state of general debility having suffered from haemoptysis and haematemesis. She died in January, 1959.

Case 5.-A man aged 40 years presented with profound anaemia in June, 1958. Investigations established the diagnosis of acute myeloid leukaemia. He was treated with 6-mercaptopurine, methotrexate, prednisolone, triamcinolone, and repeated blood transfusions. A persistent tachycardia was present throughout his illness. His final admission to hospital was on February 14, 1959, when he complained of increasing dyspnoea and cough with small quantities of mucoid sputum. These symptoms persisted, and three days before his death on March 10, 1959. pyrexia and a rising pulse rate developed.

\section{Pathological Findings}

Macroscopic Appearances.-We consider it unnecessary to describe detailed post-mortem findings apart from those changes which were due to the aspergillus. No definite residual Hodgkin's disease could be discovered at necropsy in Case 1 . Cases
$2,3,4$, and 5 did not show any features unusuofio for patients dying of leukaemia, except for the fungal infections.

Four cases had non-suppurative lesions with distinctive naked-eye and microscopic features. In Case 2 the lesions were suppurative and abscesses had formed in several organs.

Non-suppurative Lesions.-The smallest pul- $\frac{\overline{\overline{3}}}{3}$ monary fungal lesions were firm, deep-red nodules with opaque, pale yellow centres. Such foci wereơ. scattered widely through both lungs in Cases 3 and 4. A larger lesion was found in the left lower lobeo of Case 5. It consisted of a lobulated, opaque, yellowish-grey mass, irregular in outline and surrounded by a red zone of hyperaemia. Someo carbon pigment was trapped in the central area, producing a black speckling. The appear-은 ances of this lesion suggested a confluences of smaller nodules; small independent foc을. were present in the surrounding lung (Fig. 9). In Case 1 there was a still larger area of lung involvement. The affected tissue was firm and deep red (Fig. 10). On its cut surface the lesion had indefinite margins and there were many irregularo opaque yellowish patches similar to those seen ib the smaller foci already described; the bronch $\bar{\sigma}$ were moderately dilated and contained mucoid? secretion and friable brownish material (showno microscopically to be fungal mycelium). These. changes were found in the right lung. The lef 

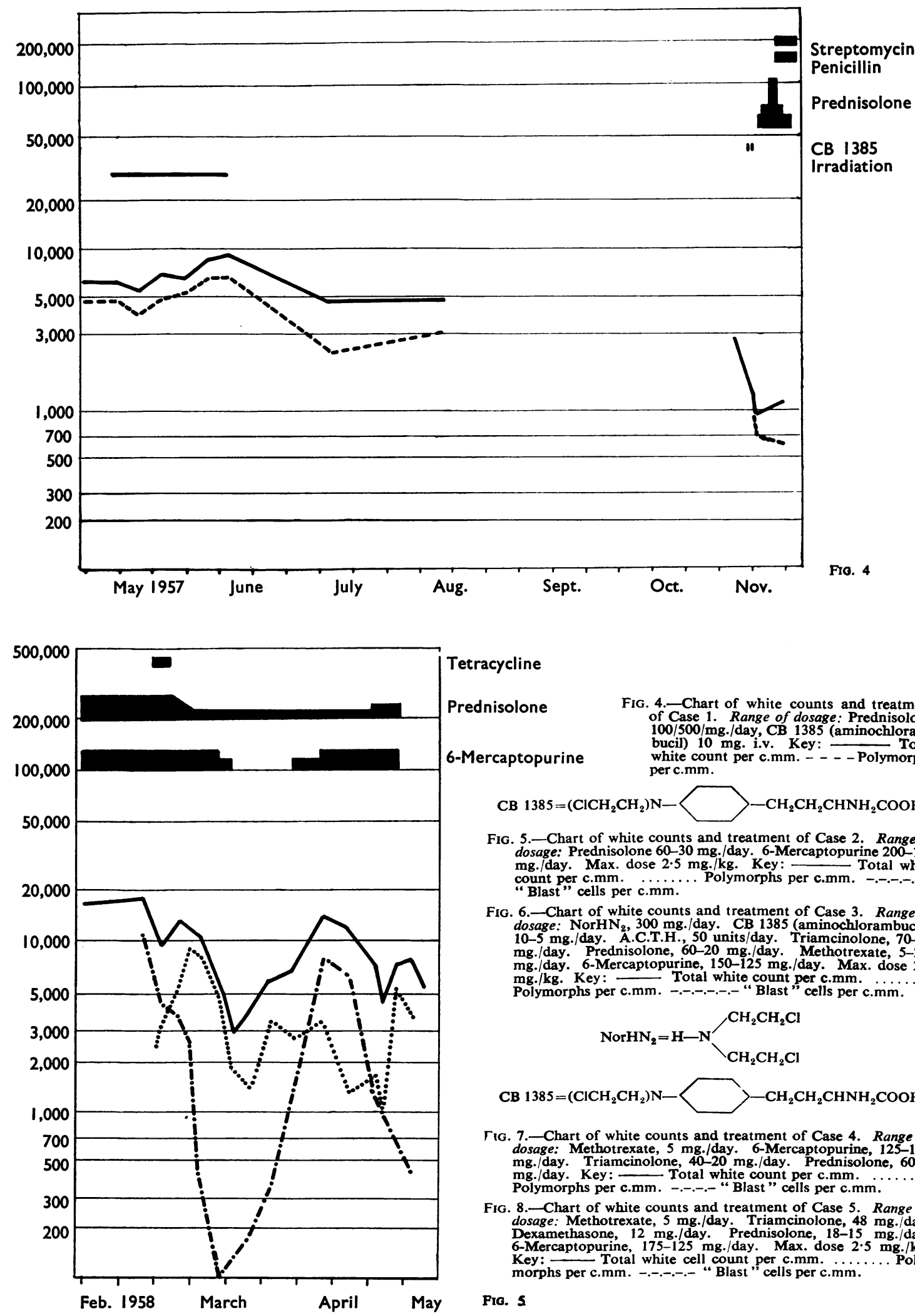

Tetracycline

Prednisolone

FIG. 4.-Chart of white counts and treatment of Case 1. Range of dosage: Prednisolone $100 / 500 / \mathrm{mg}$./day, CB 1385 (aminochlorambucil) $10 \mathrm{mg}$. i.v. Key: - Total 6-Mercaptopurine white count per c.mm. - - - Polymorphs per c.mm

$\mathrm{CB} 1385=\left(\mathrm{ClCH}_{2} \mathrm{CH}_{2}\right) \mathrm{N}-\longrightarrow-\mathrm{CH}_{2} \mathrm{CH}_{2} \mathrm{CHNH}_{2} \mathrm{COOH}$.

FIG. 5.-Chart of white counts and treatment of Case 2. Range of dosage: Prednisolone 60-30 mg./day. 6-Mercaptopurine 200-100 mg./day. Max. dose $2.5 \mathrm{mg}$./kg. Key: Total white count per c.mm. ........ Polymorphs per c.mm. -......... "Blast" cells per c.mm.

FIG. 6.-Chart of white counts and treatment of Case 3. Range of dosage: NorHN $\mathrm{N}_{2}, 300 \mathrm{mg}$./day. CB 1385 (aminochlorambucil) 10-5 mg./day. A.C.T.H., 50 units/day. Triamcinolone, 70-12 mg./day. Prednisolone, 60-20 mg./day. Methotrexate, 5-2.5 mg/day. 6-Mercaptopurine, 150-125 mg./day. Max. dose 2.5 mg./kg. Key: Total white count per c.mm. ........ Polymorphs per c.mm.

$$
\text { NorHN } H_{2}=\mathrm{H}-\mathrm{N} / \mathrm{CH}_{2} \mathrm{CH}_{2} \mathrm{Cl}
$$

CB $1385=\left(\mathrm{ClCH}_{2} \mathrm{CH}_{2}\right) \mathrm{N}-\longrightarrow-\mathrm{CH}_{2} \mathrm{CH}_{2} \mathrm{CHNH}_{2} \mathrm{COOH}$.

TIG. 7.-Chart of white counts and treatment of Case 4. Range of dosage: Methotrexate, $5 \mathrm{mg}$./day. 6-Mercaptopurine, 125-100 mg./day. Triamcinolone, $40-20 \mathrm{mg}$./day. Prednisolone, $60-5$ mg./day. Key: - Total white count per c.mm. ........ Polymorphs per c.mm. Total white count per c.mm. ...

Fig. 8. - Chart of white counts and treatment of Case 5. Range of dosage: Methotrexate, $5 \mathrm{mg}$./day. Triamcinolone, $48 \mathrm{mg}$./day. Dexamethasone, $12 \mathrm{mg}$./day. Prednisolone, 18-15 mg./day. 6-Mercaptopurine, $175-125 \mathrm{mg}$./day. Max. dose $2.5 \mathrm{mg}$./kg. Key: - Total white cell count per c.mm. ........ Polymorphs per c.mm. -..-.-.-.- " Blast" cells per c.mm.

Pio. 5 


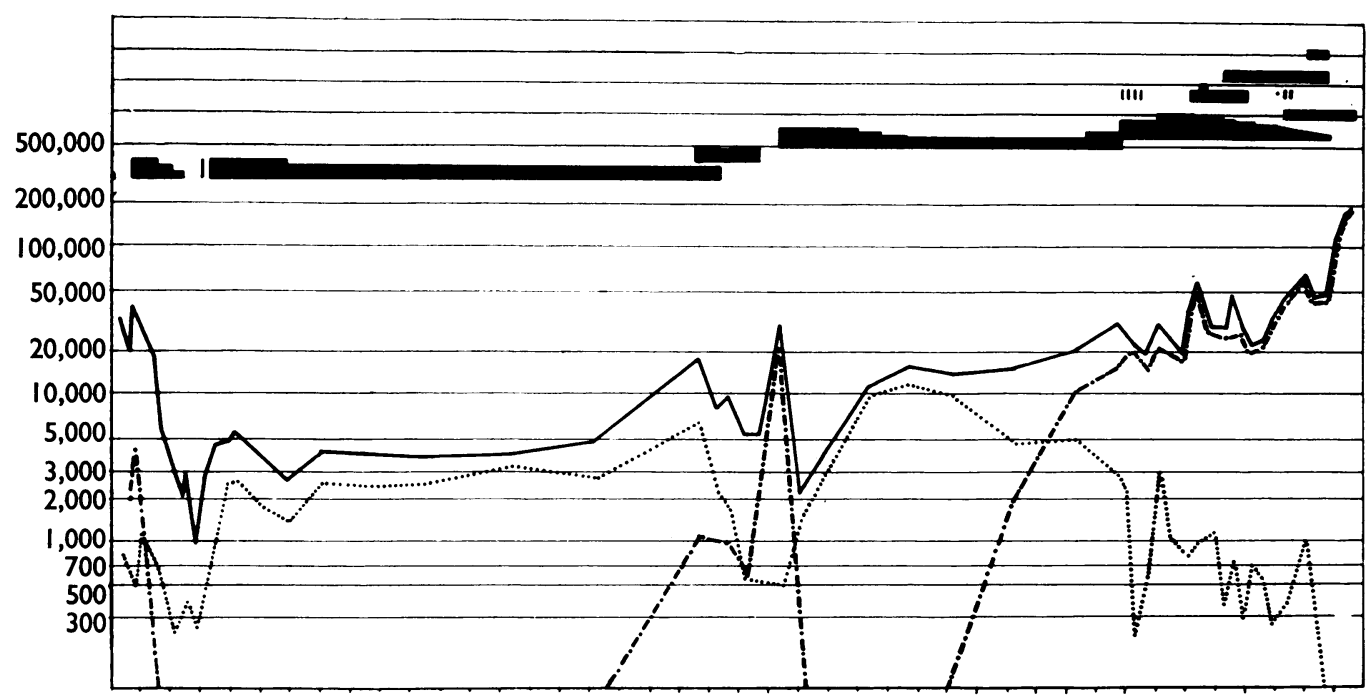

June '57 July Aug. Sept. Oct. Nov. Dec. Jan. '58 Feb. March April May June July

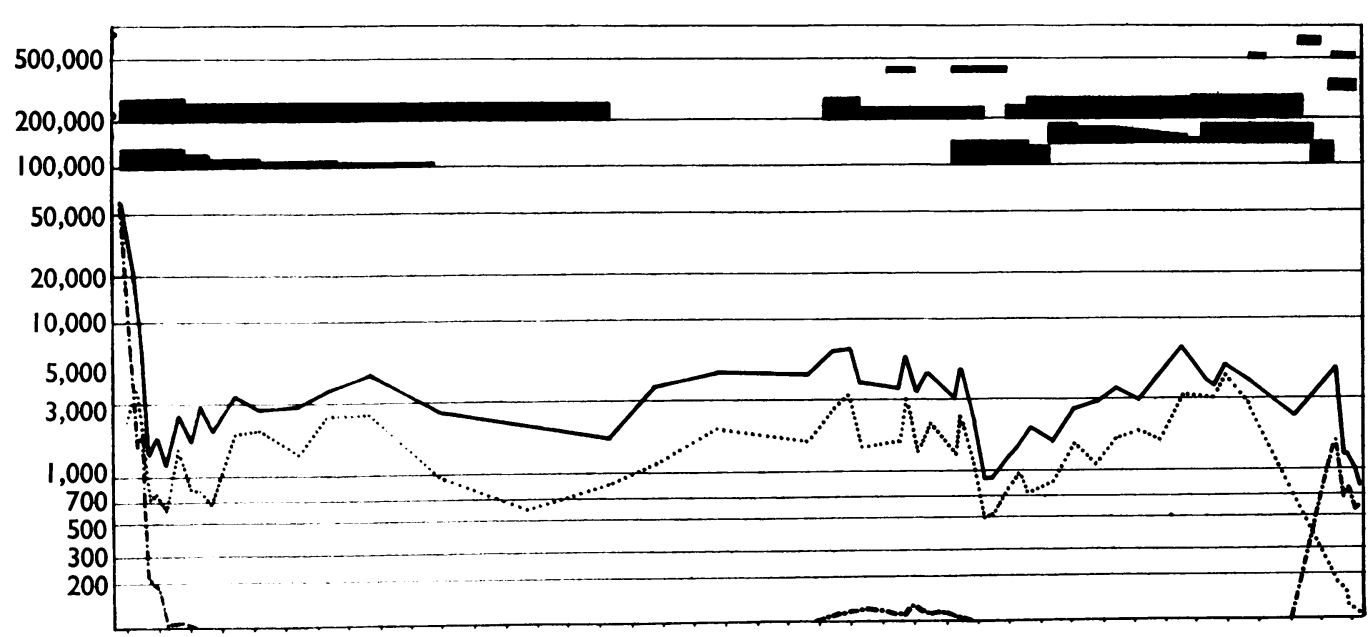

Penicillin

Penicillin $\mathrm{O}$ Tetracycline $\rightarrow$ Methotrexate 6-Mercaptopurine Triamcinolone

Prednisolone

Dec.'57 Jan.'58 Feb. March April May June July Aug. Sept. Oct. Nov. Dec.

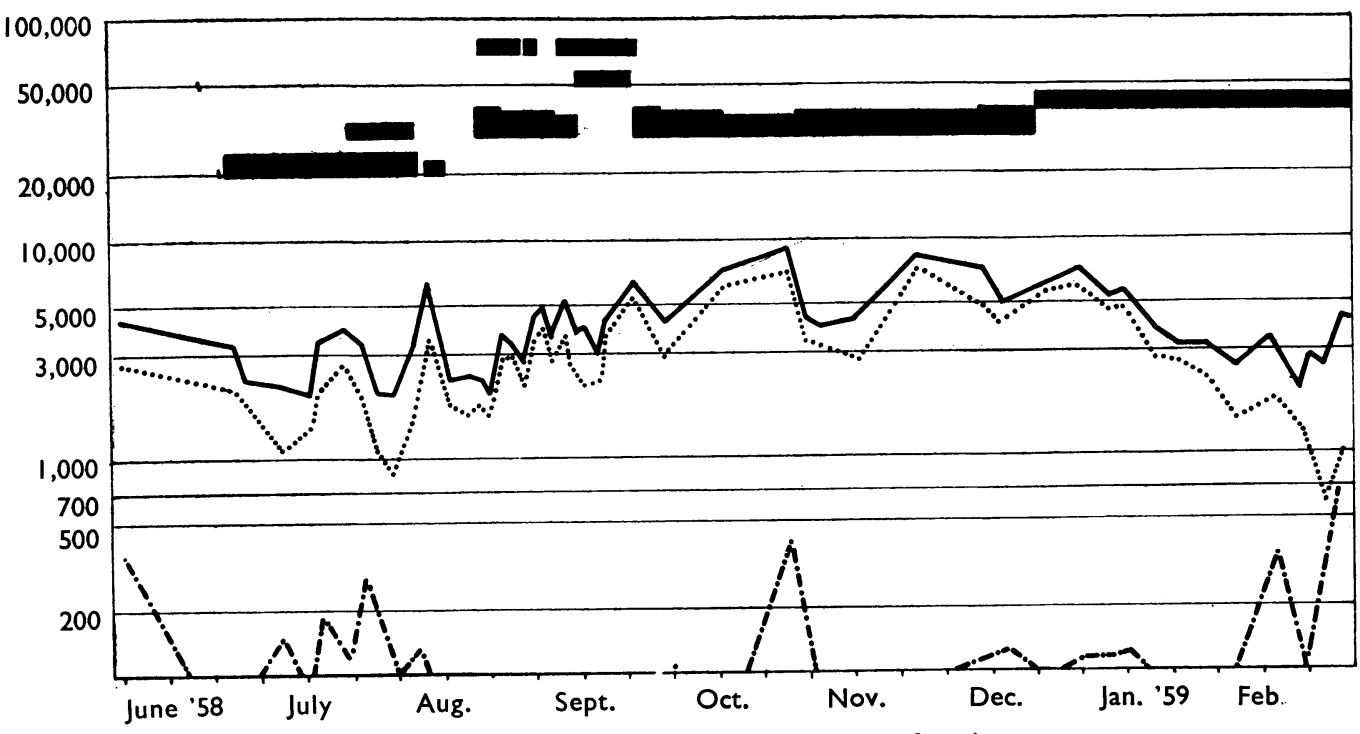

Methotrexate $\dot{\sigma}$ Triamcinolone 3 Dexamethasone Prednisolone 3 6-Mercaptopurioge

Fig. 7

-Mercaptopur

(See p. 399 for legends to figures) 


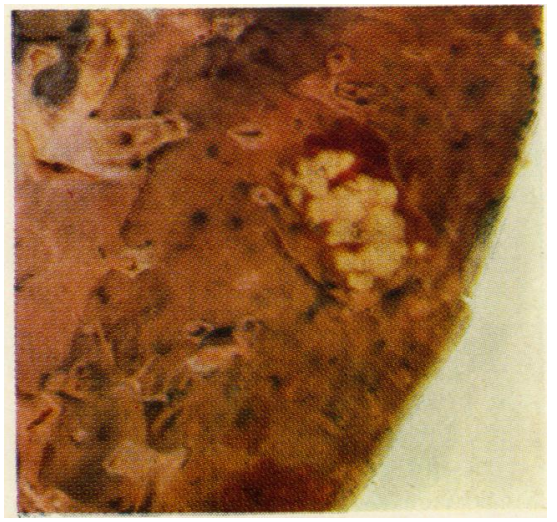

FIo. 9

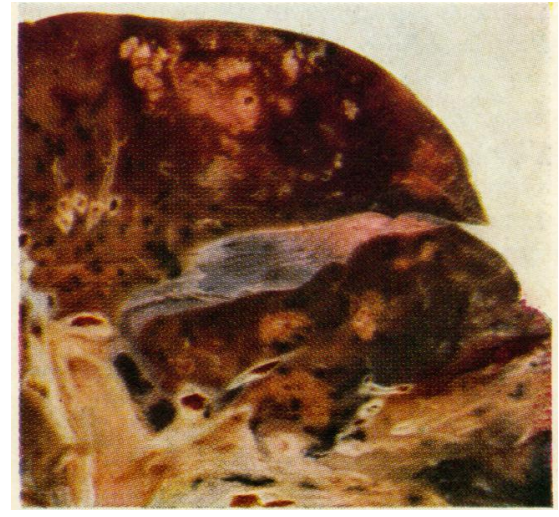

Fio. 10

Fig. 9.-Case 5. Cut surface of left lower lobe showing necrotic lesion with peripheral hyperaemia. Smaller independent foci are also present.

Fig. 10.-Case 1. Cut surface of right lung showing deep red, haemorrhagic area with multiple necrotic foci.

lung contained staphylococcal abscesses and there was a small left-sided empyema. No tissue liquefaction or cavitation was seen in any of the non-suppurative lesions. In Case 3 the trachea and main bronchi showed small mucosal ulcers with yellowish bases and red borders. Similar lesions were present in the mucosa of the laryngopharynx and stomach. In Case 4 there was involvement of the brain. A few patches of haemorrhage were present beneath the pia arachnoid over the cerebral hemispheres. There were two small patches of necrosis with haemorrhage in the left parietal lobe and a tiny area of similar haemorrhagic necrosis in the upper part of the pons over its ventral aspect.

Suppurative Lesions. - Case 2 had disseminated aspergillosis with involvement of the lungs, pericardium, myocardium, spleen, kidneys, thyroid, and liver. The pulmonary lesions were small, discrete yellowish nodules distributed throughout both lungs. The pericardial sac contained about $200 \mathrm{ml}$. of blood-stained fluid, and a thick fibrinous exudate covered the serosal surfaces of the pericardium and epicardium. A few tiny abscesses, containing yellow pus, were found deep in the posterior wall of the left ventricle. Small abscesses were present in the spleen, which weighed $213 \mathrm{~g}$. There were multiple cortical abscesses in the kidneys (right 283 g., left 265 g.). The upper half of the right kidney contained a deep red infarct. Both lobes of the thyroid were enlarged and deeply congested: no suppuration was observed on naked-eye examination. The liver was pale, but the fungal lesions were of microscopical dimensions only.

\section{Histological Observations}

The naked-eye changes in Cases $1,3,4$, and 5 correspond to a characteristic microscopic pattern of necrosis without suppuration. All the lesions in Case 2 show polymorph infiltration and pus formation. The non-suppurative and suppurative types of tissue reaction will be described separately.

Non-suppurative Lesions.-Not only do these lesions fail to suppurate but they display little evidence of any inflammatory cell response. We have designated this type of reaction as "spreading-necrotizing," a term which emphasizes the chief features. The fungal infection was confined to the lungs in Cases 1 and 5. In Case 3 there were also small foci in the trachea, pharynx, and stomach, and in Case 4 early lesions were found in the meninges and brain (Table I). It appears that the fungus can reach the pulmonary alveoli in two ways: (1) By aspiration into the respiratory bronchioles and alveolar ducts with subsequent direct spread into the associated alveolar sacs and alveoli; (2) by colonizing the mucosa of the bronchi and then spreading through their walls. The examination of multiple blocks prepared from foci of different sizes enables one to reconstruct the evolution of the lesions and to study the effect of the fungus on various tissue components.

Alveolar Foci.-Under this heading we shall consider the lesions produced when the organism spreads into the lung parenchyma by the first of the two pathways mentioned. The macroscopic appearances of the early foci have already been described as small, often widely scattered, firm nodules which are deep red with yellowish centres. Microscopically each focus has a central area of 
coagulation necrosis, appearing pink and granular in haematoxylin and eosin preparations. Fungal hyphae, staining bluish with haematoxylin, ramify in the necrotic debris. Cell outlines are lost but there may be numerous hyperchromatic nuclear fragments. Surrounding this central area there is a zone of consolidation. Here the alveoli are filled with fibrinous exudate; the capillaries are dilated and the alveolar lining cells may be prominent and cuboidal. Sometimes a few fibroblasts are seen in the exudate, indicating early organization. This is confirmed by silver impregnation which reveals delicate reticulin fibrils amidst the exudate. Apart from a few lymphocytes, some macrophages and a very occasional plasmacyte, inflammatory cells are absent. At the periphery of the consolidated area there is a zone of intense vascular engorgement and intra-alveolar haemorrhage. Occasionally the alveolar exudate may be chiefly serous in character although this is rare and fibrin is usually abundant. Thus the typical early focus shows three zones: central necrosis, fibrinous consolidation, peripheral hyperaemia and haemorrhage (Figs. 11 and 12). As the fungus grows and thrusts its hyphae outwards, the zone of necrosis enlarges. The consolidated alveoli are overwhelmed, their cells are destroyed, their outlines become blurred and incorporated into the necrotic centre, whilst fresh fibrinous exudation occurs further out. As the necrosis extends into the consolidated alveoli the fibrin loses its fibrillary structure and characteristic staining reactions, becoming merged into the general granular debris. Thus special stains, such as Mallory's phosphotungstic acid haematoxylin or Lendrum's acid picro-Mallory method, consistently fail to reveal fibrin in the central zone. Although the necrosis usually effaces the alveolar outlines completely (in haematoxylin-and-eosin-stained sections) they may be preserved even throughout large lesions (Fig. 13). The fungus itself often shows degenerative changes such as swelling and fragmentation of the hyphae. This is most marked at the centre of the necrotic area where the mycelium tends to lose its affinity for haematoxylin and stains poorly in periodic-acid-Schiff preparations. Silver impregnation for reticulin and stains for elastic fibres show considerable preservation of these structures within the necrotic mass, although progressive fragmentation does tend to occur. Perls' reaction often reveals some haemosiderin at the periphery of the focus but little or none within the central zone. In summary, the lesion may be described as a centrifugally spreading coagulative necrosis, the advancing front being preceded by zones of fibrinous exudation, hyperaemia, and haemorrhage.
Bronchial Lesions. - Fungal mycelia grow within bronchial lumina and in this situation: sporing heads may be seen (Fig. 14). There is $\overrightarrow{\vec{c}}$ marked tendency for the aspergillus to spreat through the bronchial walls into the adjacent lunge The earliest evidence of such penetration is an area of coagulation necrosis involving the epi $\overrightarrow{\mathbb{D}}$ thelium and underlying connective tissue cells (Fig. 15). Such a segment appears granular and? highly eosinophilic except in so far as there arẹ scattered, deeply basophilic nuclear fragments. Beyond the limits of the necrosis the smooth muscle fibres are separated by oedema and the mucous glands are often greatly distended. The fungus then penetrates the dead tissue and extend $\vec{\omega}$ outwards, a wave of necrosis preceding immedie ately before it. In this manner the whole thicknesso of the bronchial wall becomes necrotic and the hyphae reach the surrounding alveoli where they excite fibrinous exudation and haemorrhage a $\vec{\varepsilon}$ already described (Fig. 16). The alveoli underg $\Phi$ necrosis in their turn and so the lesion extend $\Phi_{0}$ until a large volume of lung tissue may b] involved. When passing through the bronchia wall, the fungus may grow outwards between

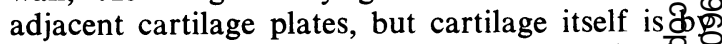
no means immune to invasion by the hyphae (Fig. 17). When such invasion takes place, क्षेe cartilage matrix loses its basophilia and metachromasia with thiazine dyes, so that it staing a uniform pink in haematoxylin and eosin prepara跇 tions. The cells nearest the fungal filament\& exhibit cytoplasmic swelling and vacuolation; th $\vec{E}$ nuclei undergo karyorrhexis or pycnosis. The cartilage plate shows progressive blurring of its outlines until it merges into the necrotic mass an can no longer be identified in haematoxylin and eosin sections. Silver impregnation usually revealo retention of a reticulin framework in the bronchia wall and the hyphae can be seen ramifying in the interstices of the argyrophilic mesh.

Vascular Lesions.-Invasion of blood vesselg by aspergillus has been noted by several authors (McKee, 1950 ; Pesle and Monod, 1954 ; Oehler. and Düffel, 1958; Finegold et al., 1959; Najî̆ 1959). We found involvement of small to medium sized arteries and veins in all our cases. ThS smooth muscle and connective tissue cells of th: vessel walls undergo coagulative necrosis and tho fungus passes through into the lumen. The walls lose their normal structure and appear simply as eosinophilic rings, although the remains of elastie. laminae can be demonstrated by suitable stainso Sometimes the junction between the affected an $\bar{\Phi}$ unaffected segments is remarkably sharp, and the 


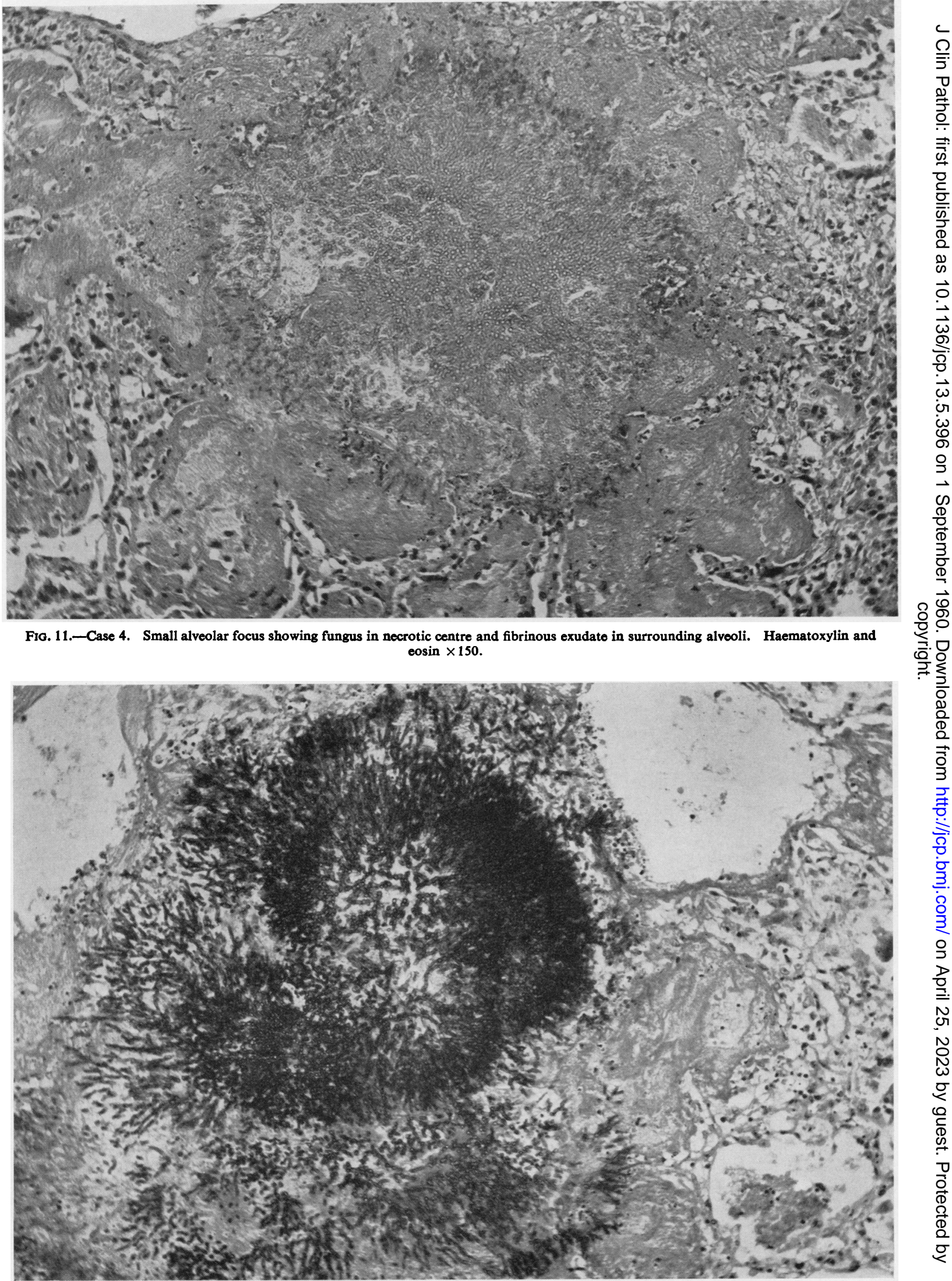

Frg. 12.-Case 4. Similar lesion to that illustrated in Fig. 11. Fungus coloured bright red in original section: black in photograph. Periodic acid-Schiff, haemalum $\times 150$ 


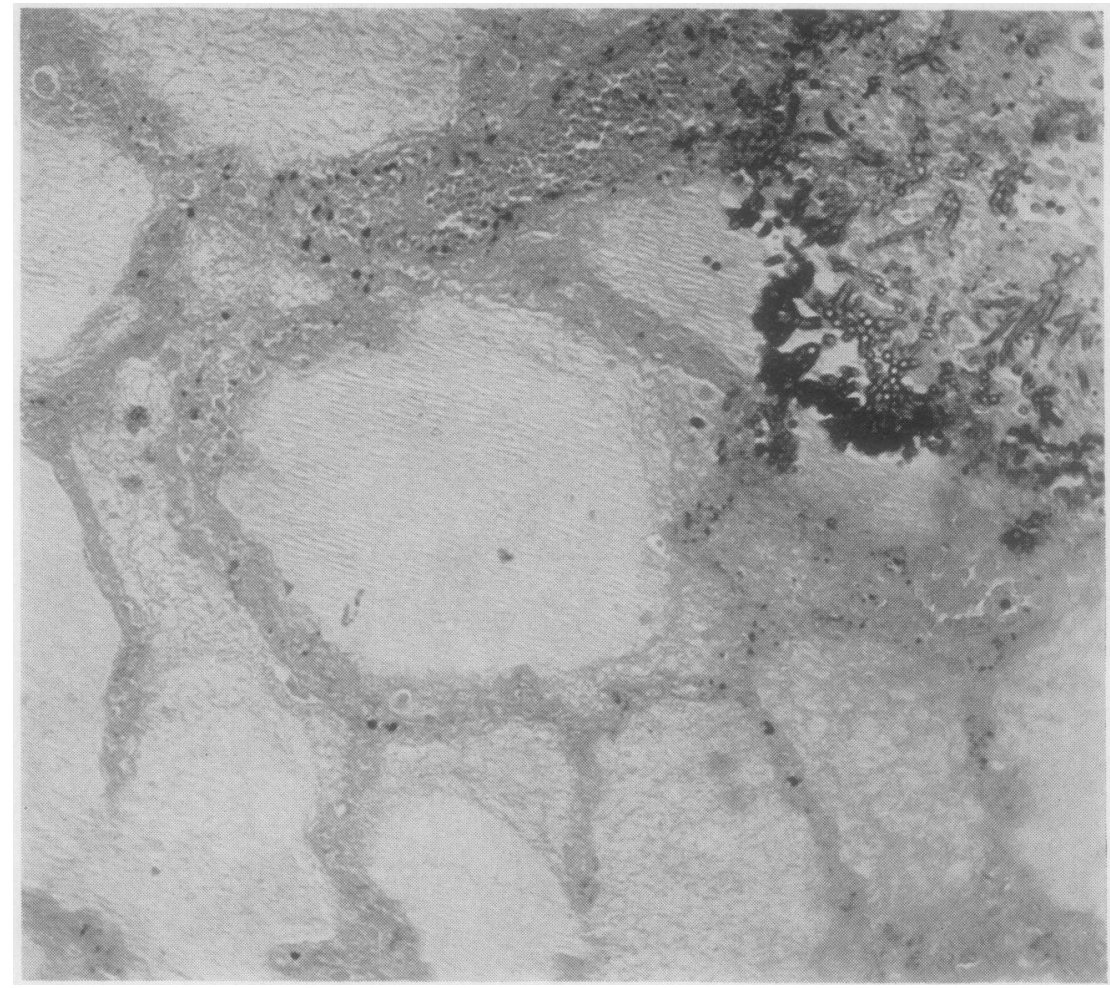

Fig. 13.-Case 1. Fungus growing in necrotic lung tissue. Alveolar outlines preserved. Haematoxylin and eosin $\times 160$.

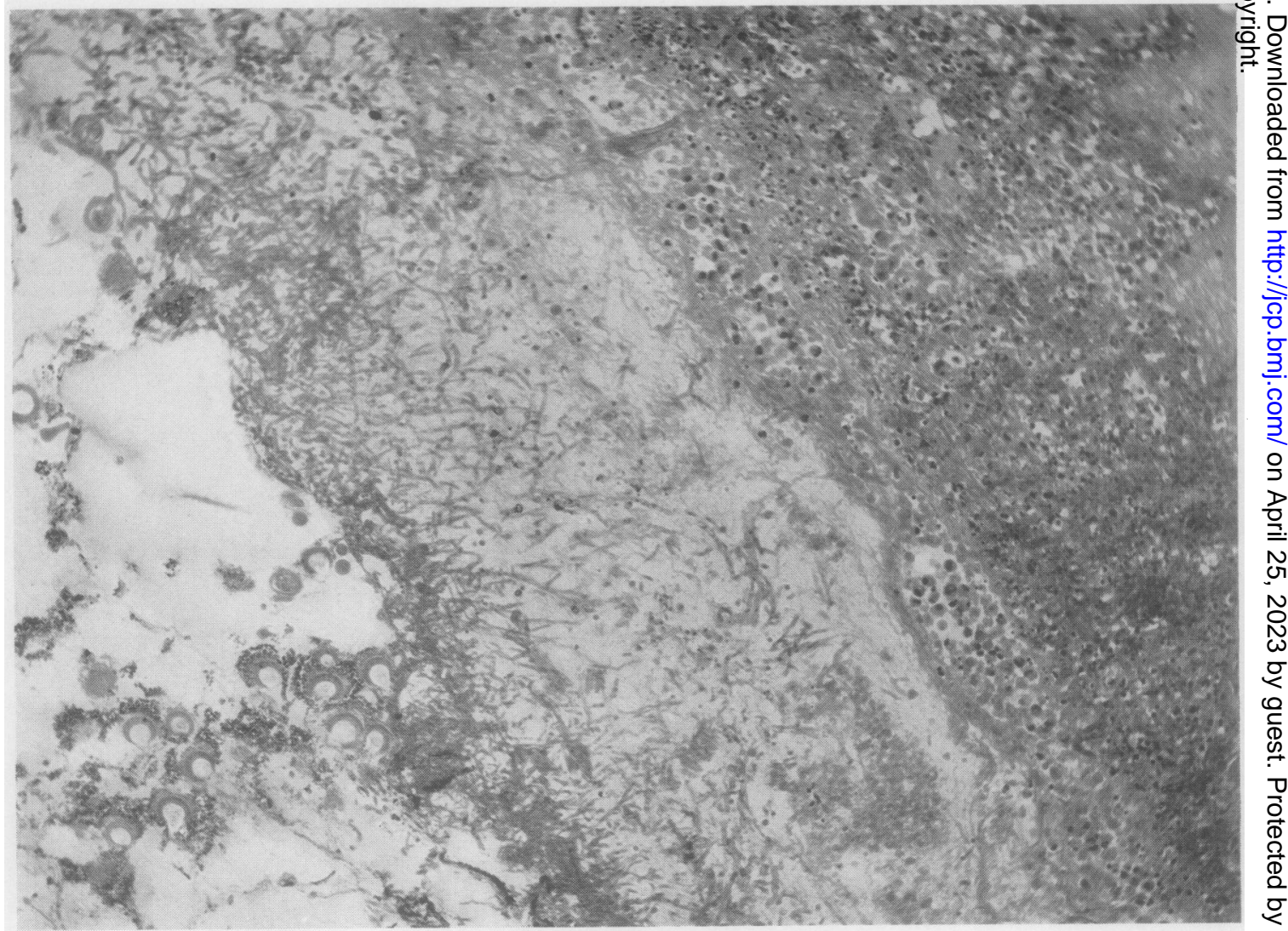

FIG. 14.-Case 1. Section through disorganized bronchus and adjacent necrotic lung tissue. Sporing heads are present in the lumen and hyphae have penetrated the bronchial wall. Haematoxylin and cosin $\times 150$. 


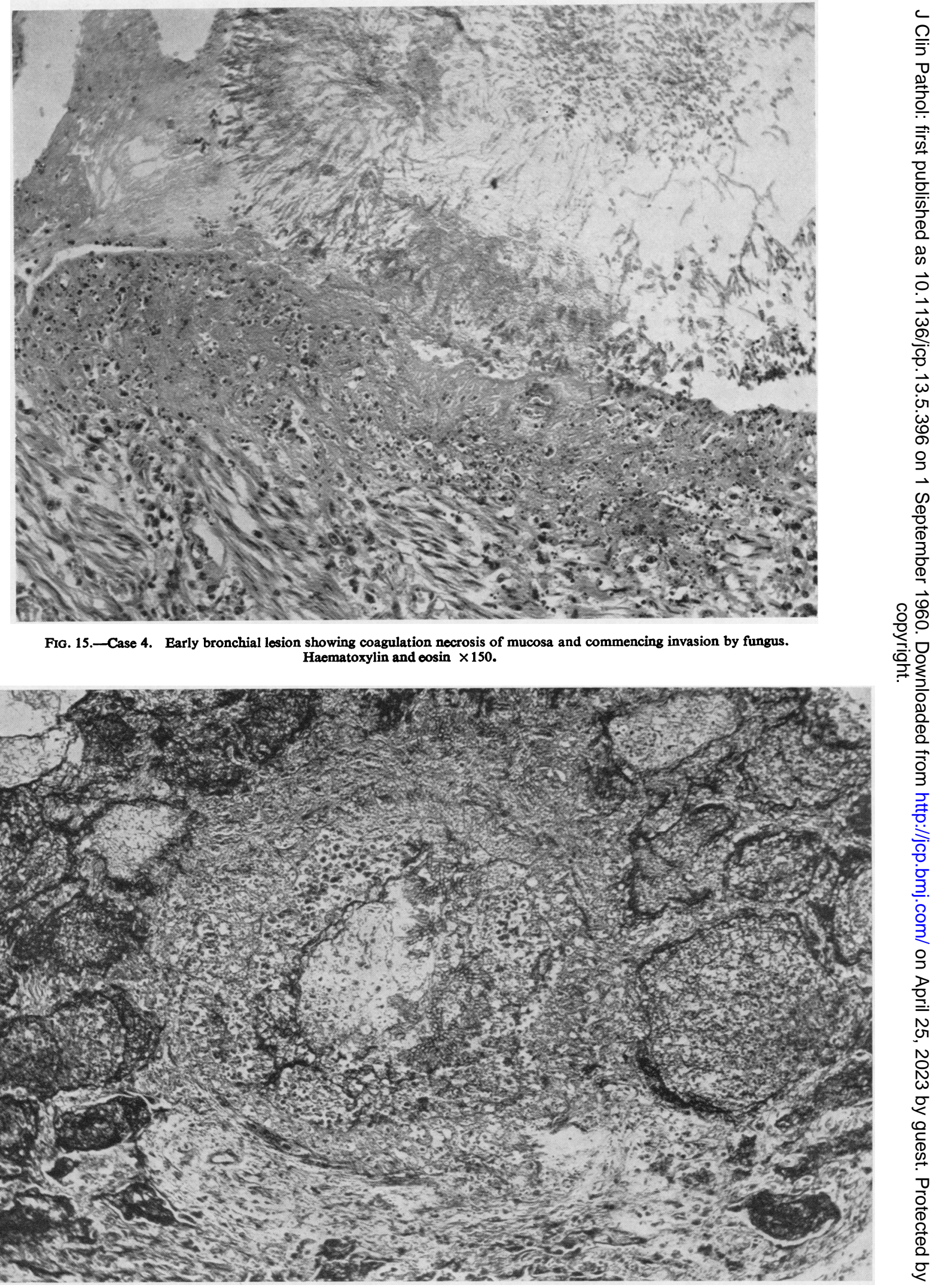

Fig. 16.-Case 1. Transverse section of a small bronchus showing hyphae in the lumen, complete disorganization of the wall, and abundant fibrinous exudate in surrounding alveoli. Fibrin coloured deep blue in original preparation: black in photograph. Phosphotungstic acid-haematoxylin $\times 75$. 


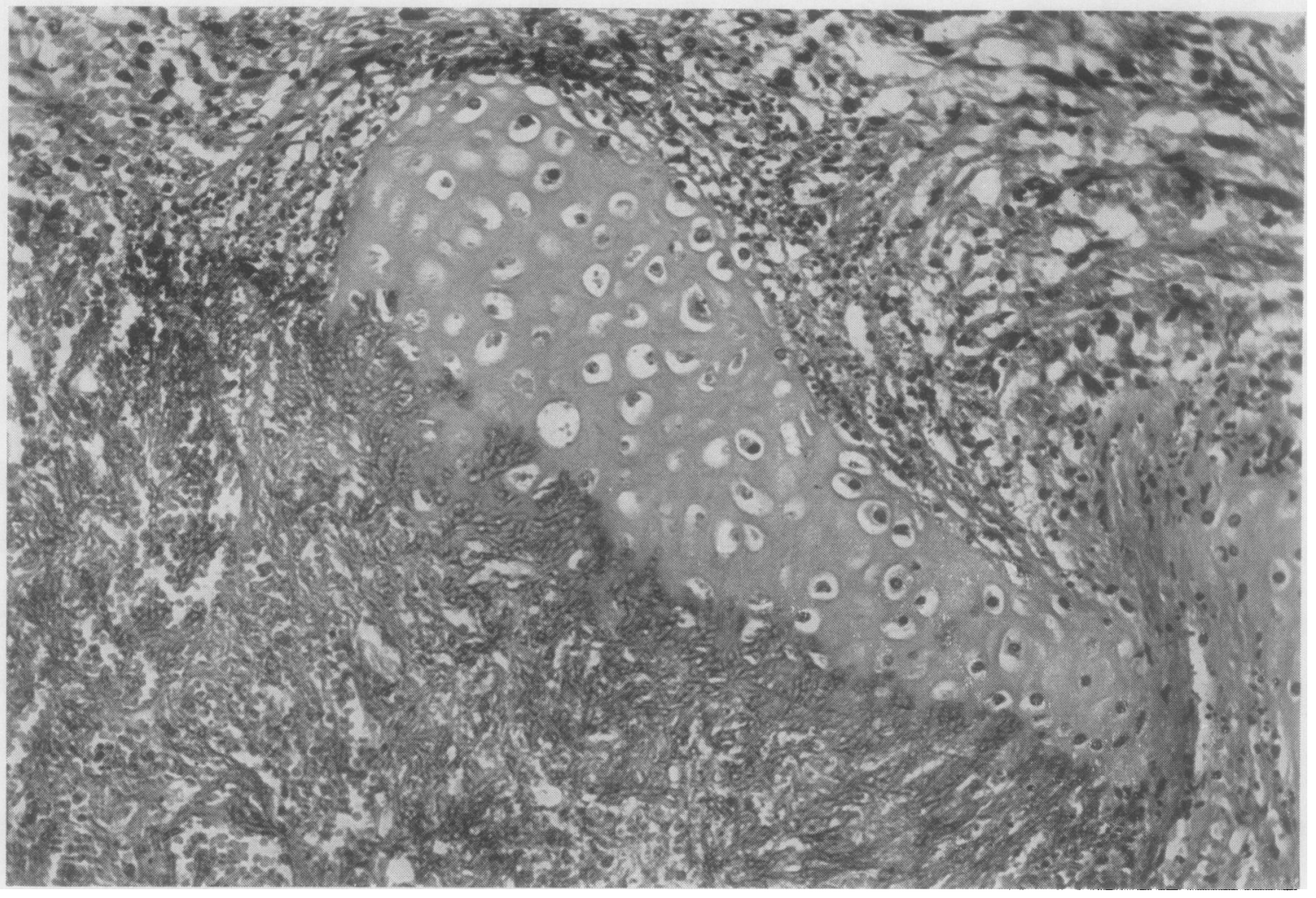

FIG. 17.-Case 4. Invasion and partial destruction of bronchial cartilage by fungus. Haematoxylin and eosin $: 216$.

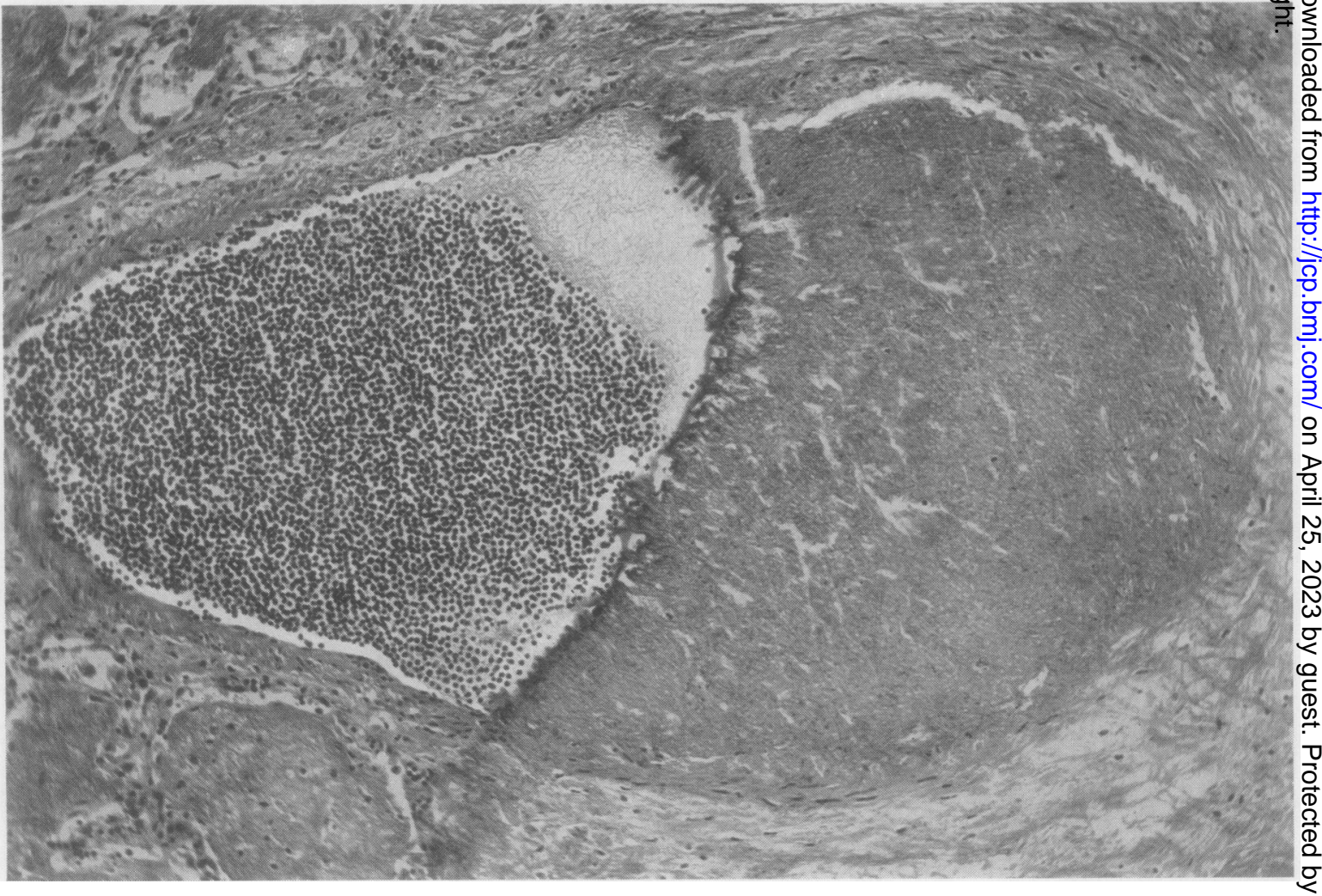

Fig. 18.-Case 3. Pulmonary blood vessel partly destroyed and occluded by fungus. Note leukaemic cells in vessel lumen and the exudate in the alveoli. Haematoxylin and eosin $\times 75$. 
way in which the mycelium engulfs the vessel, destroying the tissues but leaving vague structural outlines in its wake, is reminiscent of the earth's shadow crossing the moon during a lunar eclipse. Such an "eclipsing" lesion is shown in Fig. 18. Within the lumina the hyphae often lose their basophilia and stain pink with eosin, contrasting with those portions of the fungus that are still extravascular. Whether this change of staining property is due to the deposition of eosinophilic material upon the hyphae or to some other cause is uncertain. Suitable staining procedures sometimes show a halo of radiating fibrin filaments around the hyphae (Fig. 19). However, we wish to stress that the material occluding the vascular lumina in our cases consists of fungus and an eosinophilic granular precipitate containing very little fibrin. So that, although other workers refer to "thrombosis" of vessels invaded by aspergillus, the occlusive lesions seen in our specimens have neither the morphology nor the tinctorial properties of ordinary fibrin thrombi. Vascular obstruction may be an important factor in the pathogenesis of the necrosis which characterizes the fungal invasion, but a study of small lesions suggests that toxic products may also cause tissue death by direct action. Massive lesions such as those seen in the lungs of Case 1 and the kidney of Case 2 probably result from a combination of both factors, ischaemic and toxic. Hinson et al. (1952) refer to the invasion of infarcts by aspergillus and speak of such lesions as saprophytic. While this may well occur, it seems certain that the fungus itself is able to produce large infarct-like areas of necrosis, especially in the lungs (Fig. 13).

Gastric Lesions.-Sections of the ulcers from Case 3 show a non-suppurative tissue reaction basically similar to that already described for the lungs. Within the lesions, the mucosa has undergone coagulation necrosis to form an eosinophilic mass devoid of nuclei but still retaining vague tubular outlines. The fungus is growing in the necrotic tissue and has penetrated into the submucosa where many blood vessels have been invaded. Vascular dilatation, sero-fibrinous exudation, and red cell extravasation are prominent in the submucous layer (Fig. 19).

Cerebral Lesions.-In Case 4 there is focal involvement of the leptomeninges, the fungus being present within the lumina of small blood vessels. The vessels are dilated and there is a sero-fibrinous exudate in the subarachnoid space. Inflammatory cells are very scanty. Hyphae have penetrated the vessel walls and there is early

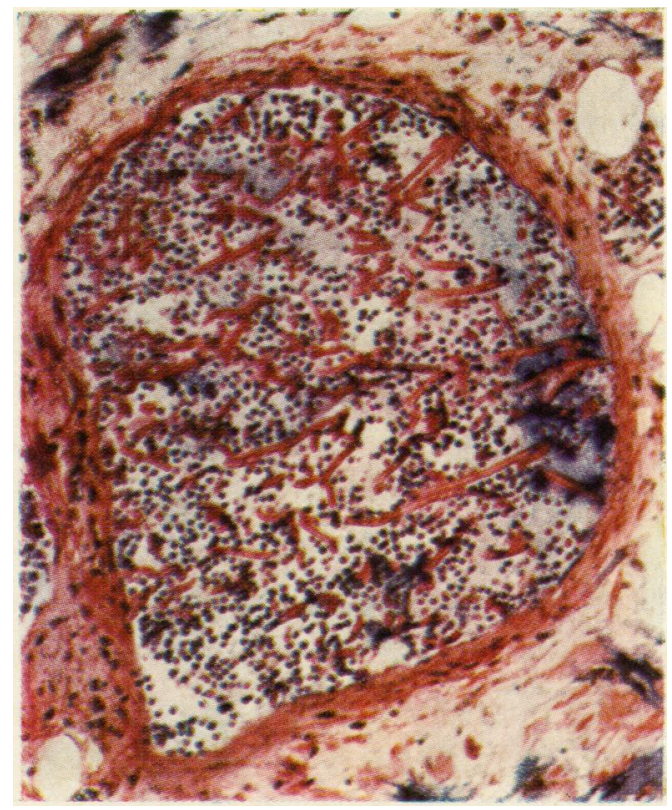

FIG. 19.-Case 3. Section showing fungus within a blood vessel of the gastric mucosa. Note the small amount of fibrin deposition around the hyphae. The adjacent connective tissue is oedematous and contains a fibrinous exudate. Fibrin coloured deep blue: hyphae, tan. Phosphotungstic acid-haematoxylin $\times 150$.

invasion of the brain substance. Small haemorrhages are present in the cortex several millimetres beyond the limits of the fungal invasion.

Suppurative Lesions. - The pulmonary lesions of Case 2 comprise numerous small, widely scattered foci of bronchopneumonia (Fig. 20). The alveolar ducts and associated alveoli are filled with an exudate rich in polymorphs amongst which swollen fungal hyphae can be identified. The lesions in the myocardium, thyroid, spleen, kidneys, and liver have the usual features of suppurative inflammation and need not be described further (Figs. 21 and 22). The pericardial exudate is composed mainly of a thick layer of fibrin, but small foci of suppuration are also present (Fig. 23). Invasion of blood vessels, with acute arteritis, is seen in several sites, but is especially prominent in the right kidney where large vessels are involved (Fig. 24). This has resulted in extensive infarction affecting the upper half of the organ.

\section{Discussion}

The following aspects will be considered: (1) The classification of aspergillosis and the distribution of the lesions; (2) factors influencing the 


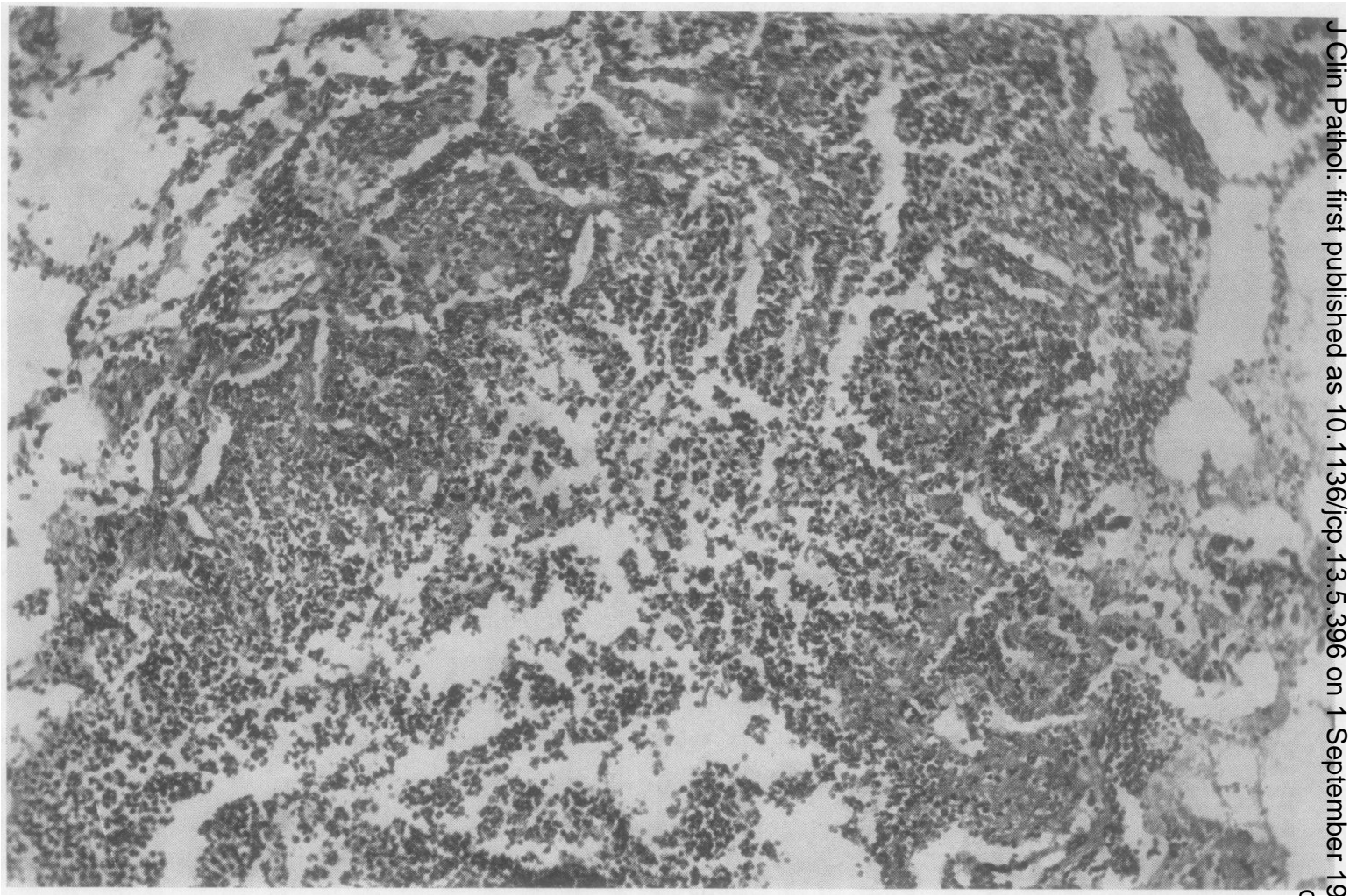

FIG. 20.-Case 2. Section of small suppurative focus in lung. Hyphae could be seen on high-power examination. Haematoxylin and eosion $\times 150$.

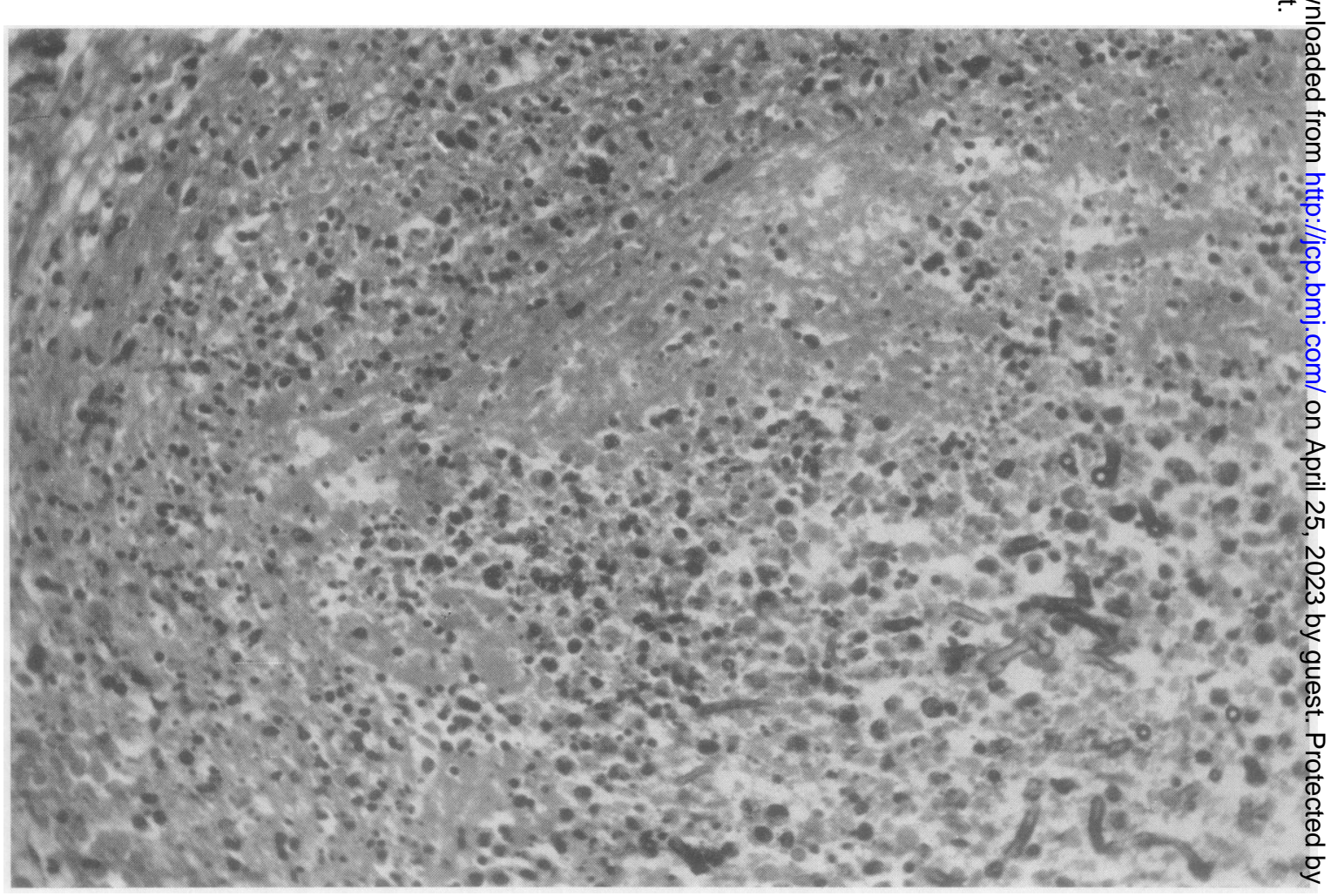

Fig. 21.-Case 2. Section of splenic abscess showing fragmented mycelium in pus. Haematoxylin and eosin $\times 430$. 


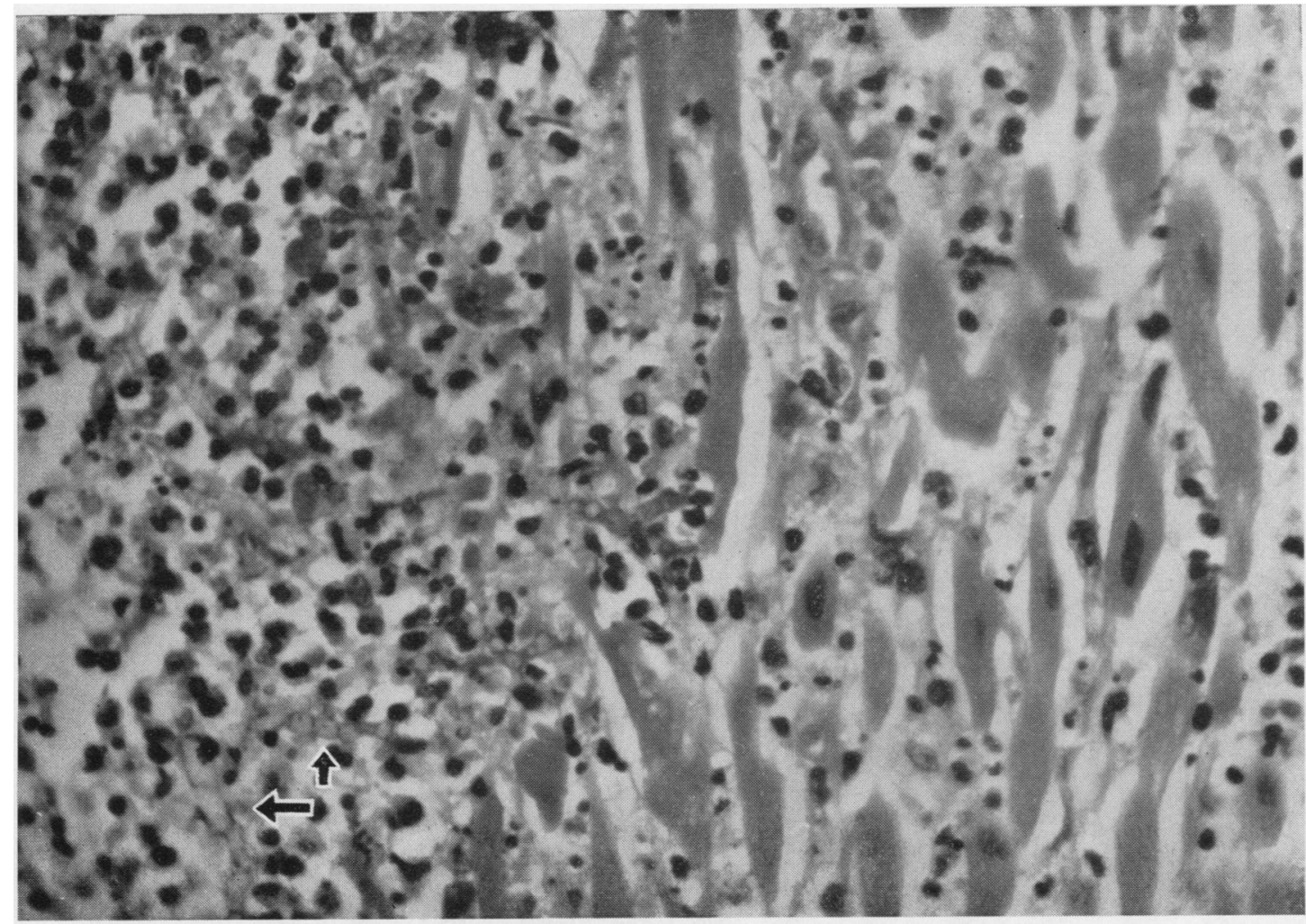

Fig. 22. - Case 2. Section of myocardial abscess showing pus cells and swollen hyphae. Haematoxylin and eosin $\times 520$.

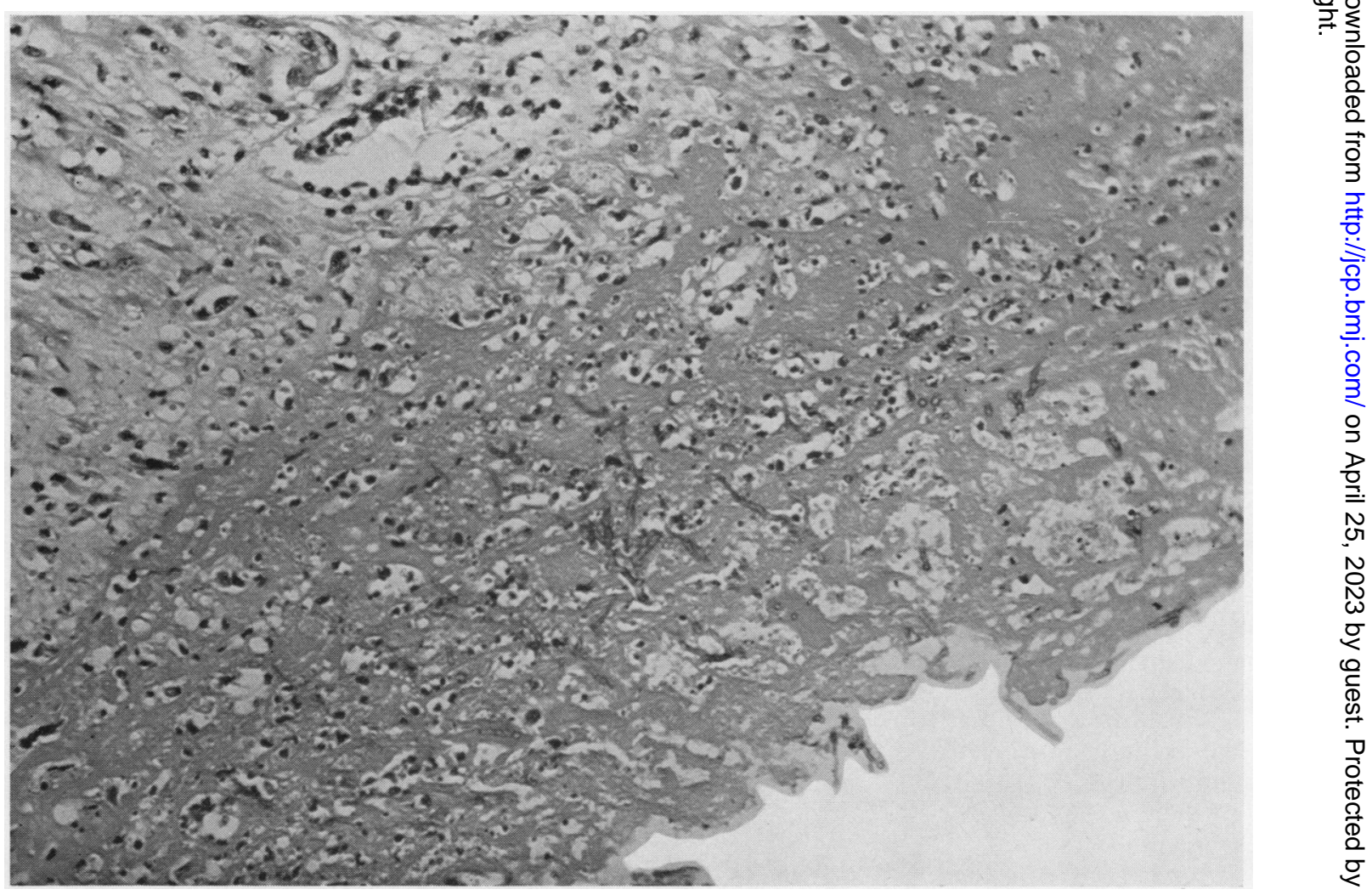

FIG. 23.-Case 2. Section of epicardium showing hyphae in fibrinous exudate. Hacmatoxylin and eosin $\times 216$. 


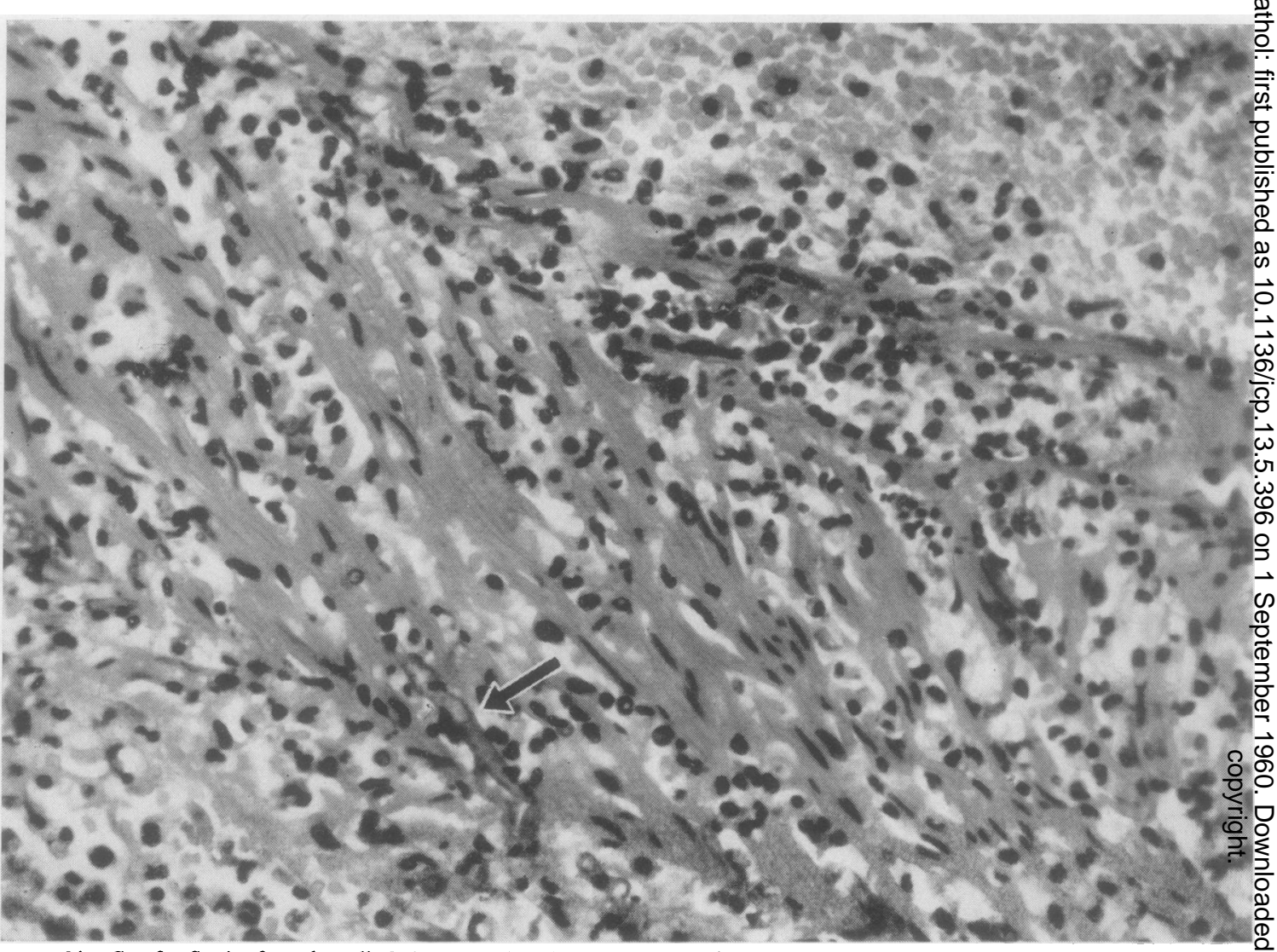

FIG. 24.-Case 2. Section from the wall of a large renal blood vessel showing oedema and polymorph infiltration of the media and the presence $\vec{F}$ of swollen hyphae. Haematoxylin and eosin $\times 430$.

invasion of the body by the fungus; (3) factors influencing the nature of the tissue reactions.

\section{Classification and Distribution of Aspergillus} Lesions.- Various classifications of aspergillosis have been suggested. These are based on $(a)$ whether the disease is secondary or primary, i.e., whether a predisposing disease is or is not present ; (b) the extent of spread (localized or disseminated); (c) the pathology of the lesion; and $(d)$ the presence or absence of allergy (Hinson et al., 1952 ; Hinson, 1958 ; Finegold et al., 1959). With regard to pulmonary disease, there are several wellcharacterized types: (1) Aspergillus bronchitis in which the fungus grows within the bronchial lumina and the mucosa shows only superficial changes (Körtge, 1952 ; Segretain, 1958) ; (2) allergic, in which the bronchi contain fungus, mucus, fibrin, eosinophils, Curschmann's spirals, and Charcot-Leyden crystals. The patients suffer asthmatic attacks and eosinophilia may be present in the peripheral blood (Hinson et al., 急 1952) ; (3) " mycetoma" or " intracavitary aspergilloma." This comprises a mycelial mass (fungus ball), usually reddish-brown, lying in a saccular dilatation of a bronchus. The bronchial epithelium is often intact and the adjacent connective tissues are infiltrated with plasmacytes, macrophages, and polymorphs in varying numbers (Monod, Pesle, 을 and Segretain, 1951 ; Pesle and Monod, 1954; Hinson, 1958 ; Naji, 1959); (4) invasive, in which 을 the fungus spreads beyond the confines of the $\bar{N}$ bronchi into the alveolar parenchyma of the lung (Lapham, 1926 ; Penta, 1955 ; Finegold et al., N 1959 ; Naji, 1959).

Spread from the lungs by the blood stream may 0 produce fungal lesions in other parts of the body 0 such as the brain, meninges, endocardium, myocardium, pericardium, kidneys, liver, spleen, $\stackrel{\mathcal{Q}}{\rightarrow}$ thyroid, lymph nodes, pancreas, and bones (see 0 review by Grcevic and Matthews, 1959). Dissemination to the brain and meninges was present 
in our Case 4. In Case 2 fungal lesions were present in the pericardium, myocardium, thyroid, spleen, kidneys, and liver. Although the respiratory tract is the usual portal of entry, the fungus can also colonize the mucosa of the alimentary tract (Welsh and McClinton, 1954 ; Zimmerman, 1955 ; our Case 3 ). It is also possible that these organisms may occasionally be introduced by therapeutic injections. Wybel (1952) reported a case of mycotic granuloma of the leptomeninges in a patient who had received intrathecal injections of penicillin for pneumococcal meningitis three years before her death. The clinical course of the granuloma simulated a spinal cord tumour.

Factors Influencing Invasion of the Body by the Fungus. - The importance of environmental (occupational) factors and of pulmonary lesions has already been mentioned. Apart from this there is evidence that tissue invasion by fungi is facilitated by the administration of various antibiotics, chemotherapeutic drugs, and hormones. Keye and Magee (1956), reviewing the incidence of fungal infections amongst 15,845 consecutive necropsies performed from 1919 to 1955 , found a conspicuous increase in the number of secondary fungous infections since 1947. Histoplasmosis, cryptococcosis, mucormycosis, candidiasis, and aspergillosis had all increased. They also noted a greater tendency to systemic dissemination of the fungi during recent years. An especially high incidence was observed in cases of leukaemia and malignant lymphoma. These authors believed that the rising frequency was related to the administration of multiple antibiotics, chemotherapeutic compounds, and cortisone. Craig and Farber (1953) observed 13 examples of disseminated visceral fungal infections amongst 175 cases of acute leukaemia in children who had come to necropsy since the introduction of anti-folic-acid compounds, triethylmelamine, cortisone, and A.C.T.H. There were 11 infections with candida and one each with mucor and cryptococcus. No case of disseminated visceral mycosis was found in untreated leukaemic children. Zimmerman (1955) also reviewed the rising incidence of fungal infections complicating other diseases. He concluded that both aspergillosis and candidiasis were increasing as a result of treatment by antibiotics, chemotherapeutic agents, and nitrogen mustards. Torack (1957) reported 13 cases of fungus infection (moniliasis, mucormycosis, and aspergillosis) associated with antibiotic and steroid therapy. His cases fell into two categories. In those patients receiving antibiotics alone, the fungi showed only surface pro- liferation; in cases where both antibiotics and cortisone had been given, the fungi actively invaded the tissues. Sidransky and Friedman (1958) saw 15 examples of secondary fungal infection amongst routine necropsies from 1955 to the end of 1957 . There were five cases of aspergillosis; each of these had received treatment with cortisone and "broad-spectrum" antibiotics. Aspergillus flavus was cultivated from three cases. Finegold et al. (1959) reported 12 cases of aspergillosis. Seven were suffering from carcinoma, leukaemia, or Hodgkin's disease. Six had been given steroids. Four had received other "anti-neoplastic" therapy including irradiation to the spleen, "myleran," "leukeran," and " amethopterin."

These clinical observations are supported by experimental studies. Huppert, MacPherson, and Cazin (1953) found that aureomycin caused a significant growth stimulation of Candida albicans in broth cultures. Seligman (1953) demonstrated enhanced virulence of Candida albicans by terramycin, aureomycin, and cortisone in experimental animals. Mankowski and Littleton (1954) found that the administration of cortisone reduced the survival times of mice infected with Candida albicans, Aspergillus sp., Penicillium sp., Histoplasma capsulatum, or Cryptococcus neoformans. Sidransky and Friedman (1959) exposed mice to aerosols containing dry, viable spores of Aspergillus flavus. Untreated animals and those given only antibiotics developed a transient pneumonitis. In those mice receiving cortisone, or cortisone and antibiotics, there was rapid germination of the spores and spread of hyphae through the lungs. The authors comment that the histological appearances in the lungs of the cortisone-treated mice closely resembled those found post mortem in human cases of pulmonary aspergillosis.

It therefore seems likely that the establishment and dissemination of aspergillus infection are dependent on a number of factors: (1) A local lesion such as bronchiectasis or a tuberculous cavity; (2) a high concentration of spores in the environment (occupational hazards) ; (3) depression of antibody and cellular defence mechanisms by generalized disease, malignant lymphomas and leukaemia being of paramount importance in this respect; (4) further depression of defence mechanisms by radiotherapy, antimetabolites, radiomimetic drugs, steroids, or A.C.T.H.; and (5) disturbance of the "normal " respiratory flora by the administration of antibiotics (Tomaszewski, 1951). We consider factors (3) and (4) to be those of greatest significance in our own cases. 
Certain Factors Influencing Nature of Tissue Reactions.-Baker (1947) and Symmers (1958) have described the various tissue reactions that may be found in fungal infections. The pattern varies with the type of fungus, its location, the duration of the lesion, the presence or absence of allergy, and the general condition of the host. According to the circumstances one or more of the following may be seen: intracellular parasitism, suppuration, chronic non-specific inflammatory changes, fibrosis, tuberculoid reactions, caseation, "foreign-body" reactions, and " no reaction." The changes most often seen in the invasive varieties of aspergillosis are necrosis, acute inflammation, and suppuration. It will be recalled that four of our cases displayed foci of coagulation necrosis associated with exudation and haemorrhage but with a virtual absence of inflammatory cells. Necrosis and haemorrhage have been reported by other workers such as Heppleston and Gloyne (1949), Rankin (1953), Naji (1959), and Grcevic and Matthews (1959). Others have described granulomatous lesions with epithelioid cells and giant cells. Such granulomas have been observed both in humans (Cawley, 1947 ; Iyer, Dodge, and Adams, 1952 ; Finegold et al., 1959) and experimental animals (Henrici, 1940 ; Cooper, 1946 ; Oehlert and Düffel, 1958). Henrici (1940) studied the lesions produced in rabbits by injecting aspergillus spores. He found that massive doses produced foci of necrosis and haemorrhage. Moderate doses led to abscess formation, while small numbers of spores resulted in "tubercles" with central caseation. In lesions of the last type, the so-called actinomycetoid form of the fungus was sometimes found. This consists of short filaments of thin mycelium radiating from a portion of normal-sized mycelium; the ends of the filaments are often capped by acidophilic material. Actinomycetoid bodies have been observed in human lesions (Oehlert and Düffel, 1958), but they were not present in our own cases. Henrici (1940) believed the epithelioid-cell granulomas and the actinomycetoid forms to be manifestations of hypersensitivity. If this is so, their absence from our cases is not surprising in view of the frequent poverty of immunological mechanisms in Hodgkin's disease (Dubin, 1947) and their impairment in leukaemia following treatment with steroids (Larson and Tomlinson, 1953). Grcevic and Matthews (1959) have also discussed the possibility of hypersensitivity reactions in patients with aspergillosis. They reported three cases of disseminated infection and described certain features which they considered indicative of hypersensitivity. The features they stressed were diffuse joint pains, symmetrical facial rash, " onion peel " arteriolar changes in the spleen, and erythrophagocytosis in lymph nodes. The lesions in their cases were acute and suppurative: no giant-cell granulomas were observed.

There is no evidence that the fungus can produce a true exotoxin, although certain toxic antibiotic and tumour-inhibiting substances have been isolated from cultures of Aspergillus fumigatus (Soltys, 1944 ; Asheshov and Strelitz, 1945 ; Petermann, Hamilton, and Reilly, 1952). Oehlert and Düffel (1958) found anisotropic crystalloid bodies within fungal networks lining the bronchi of their patient. They suggested that these crystals were toxic metabolites of the fungus. Henrici (1939) extracted a "cell sap" rich in endotoxin from Aspergillus fumigatus and Aspergillus flavus. Subcutaneous injection of the cell sap into rabbits and guinea-pigs resulted in necrosis, oedema, and polymorph infiltration. Intravenous injections produced pulmonary haemorrhages, renal tubular necrosis and lobular hepatic necrosis in rabbits ; in guinea-pigs there were nervous symptoms leading to paralysis. The sap was also haemolytic to sheep's erythrocytes. Such toxic agents, liberated from degenerating fungal filaments and diffusing into the tisues surrounding a mycelial mass, couls produce the type of tissue response observed iff our cases. Tissue damage occurring in this manner may well pave the way for further fungal invasion and the centrifugal spread of the lesion (Riddell, 1958). In four of our cases the depression of antibody and cellular defences apparently allowed the rapid development of the lesions in a "pure" state and it was possible to study the effect of the toxic substances on different tissue components without the complicating factor of an inflammatory-cell infiltrate. The diffusable toxic products can cause necrosis of epithelial cells, connective-tissue cells, and muscle fibres. They affect the ground substance of cartilage which loses its basophilia and is finally destroyed together with the chondrocytes. Reticulin, elastic fibres, and collagen are more resistant and can often be demonstrated deep in necrotic zones. Damage to blood vessels results in exudation and the extravasation of erythrocytes, while more severe effects are manifest by necrosis of the vessel walls and occlusion of their lumina. The vascular obstruction will then lead to further tissue degeneration and necrosis. We have already stressed the small amount of fibrin that could be demonstrated in the material occluding the vessels of our cases, and have described the dissolution of fibrin in the alveolar exudate as it becomes invaded by the fungus. These observations suggest a fibrino- 
lytic action of the diffusable products, and it is interesting to note that a substance having such activity has recently been isolated from Aspergillus oryzae (Stefanini, Adamis, Soardi, Horace, Marin, and Mele, 1959). On the other hand the hyphae in the pericardial exudate of Case 2 do not appear to have had any significant lytic effect on the fibrin in their vicinity, although digestion has occurred in the suppurative foci. It is possible that the large surface area of the serous membranes allows such an abundant exudation that the fibrin remains constantly in excess of any fibrinolytic substance diffusing from the fungus. The virtual absence of neutrophils from the peripheral blood during the last days of life probably accounts for the absence of suppuration in Cases $1,3,4$, and 5 . This interpretation accords with the findings of Torre and Leikin (1959). Using the Rebuck skin window test these authors demonstrated a poor inflammatory response in leukaemic patients who had significant neutropenia. However, it is interesting to recall that in our Case 1, staphylococcal abscesses were present in the lungs, so that a suppurative type of inflammatory reaction was still possible; this indicates the poor pyogenic properties of aspergillus relative to the staphylococcus under identical environmental conditions. The only patient who did not have a severe terminal neutropenia (Case 2) developed widespread suppurative lesions as already described. It is possible that the toxic substances may be absorbed into the blood stream and exert an effect on distant parts of the body. Chortis (1952) recorded his clinical impression that pulmonary aspergillosis can cause toxic effects on the myocardium and central nervous system, although he produced no pathological evidence for this statement. Oehlert and Düffel (1958) found necrosis and calcification of the renal tubules in rats that had been given intraperitoneal injections of Aspergillus fumigatus. They also described fibrinoid swelling of the walls of small and medium-sized blood vessels in the livers, kidneys, and hearts of the animals. In our own cases we have been unable to find changes in distant organs that could be attributed to toxic metabolites of the aspergillus. It may, of course, be extremely difficult to distinguish between lesions produced this way and those resulting from other factors such as anaemia, cardiac failure, and therapeutic agents.

We are indebted to Dr. P. E. Thompson Hancock, Dr. J. B. Harman, and Professor D. W. Smithers for allowing us to use the clinical notes of the patients under their care. Dr. D. Galton, Dr. H. E. M. Kay, and Dr. Eve Wiltshaw kindly gave us permission to publish the results of the various haematological investigations. We are grateful to Dr. R. W. Riddell and Dr. Yvonne Clayton for advice on the identification of the fungus. We also wish to thank Miss J. Hunt and her staff for the photographs of the gross specimens, Mr. Kenneth Moreman (of the Chester Beatty Research Institute) for the photomicrographs, Miss Cynthia Sutton, assistant medical artist, for the charts shown in Figs. 4-8, Mr. C. G. Chadwin, Miss Patricia Gates, Mr. S. Murdoch, and Mr. F. Wharton for invaluable technical assistance, and Miss B. Higgs, Secretary to the Department of Morbid Anatomy, for the preparation of the typescript.

\section{REFERENCES}

Asheshov, I. N., and Strelitz, F. (1945). Science, 101, 119.

Baker, R. D. (1947). Arch. Path. (Chicago), 44, 459.

Cawley, E. P. (1947). Arch. intern. Med., 80, 423.

Chortis, P. (1952). Dis. Chest, 22, 206.

Coe, G. C. (1945). Ann. intern. Med., 23, 423.

Cooper, N. S. (1946). Arch. Path. (Chicago), $42,644$.

Craig, J. M., and Farber, S. (1953). Amer. J. Path., 29, 601.

Dubin, I. N. (1947). Ann. intern. Med., 27, 898.

Finegold, S. M., Will, D., and Murray, J. F. (1959). Amer. J. Med., $27,463$.

Golebiowski, A. K. (1958). Tubercle (Lond.), 39, 111.

Grcevic, N., and Matthews, W. F. (1959). Amer. J. clin. Path., 32, 536.

Henrici, A. T. (1939). J. Immunol., 36, 319.

- (1940). J. Bact., 39, 113.

Heppleston, A. G., and Gloyne, S. R. (1949). Thorax, 4, 168.

Hinson, K. F. W. (1958). In Fungous Diseases and Their Treatment, p. 123., ed. R. W. Riddell, and G. T. Stewart. Butterworth, London.

Moon, A. J., and Plummer, N. S. (1952). Thorax, 7, 317.

Huppert, M., MacPherson, D. A., and Cazin, J. (1953).' J. Bact., $65,171$.

Iyer, S., Dodge, P. R., and Adams, R. D. (1952). J. Neurol. Neurosurg. Psychiat., 15, 152.

Keye, J. D., and Magee, W. E. (1956). Amer. J. clin. Path., 26, 1235

Körtge, P. (1952). Dtsch. med. J., 3, 202.

Lapham, Mary E. (1926). J. Amer. med. Ass., 87, 1031.

Larson, D. L., and Tomlinson, Lois J. (1953). J. clin. Invest ., 32, 317.

Lendrum, A. C. (1949). J. Path. Bact., 61, 443.

Mankowski, Z. T., and Littleton, Bobbe J. (1954). Antibiot. and Chemother., 4, 253.

McKee, E. E. (1950). Amer. J. clin. Path., 20, 381.

Monod, O., Pesle, G., and Segretain, G. (1951). Bull. Acad. nat. Méd. (Paris), 135, 508.

Naji, A. F. (1959). A.M.A. Arch. Path., 68, 282

Oehlert, W., and Düffel, F.(1958). Zbl.allg. Path.path. Anat., 98, 41.

Penta, A. Q. (1955). Amer. J. Surg., 90, 77.

Pesle, G. D., and Monod, O. (1954). Dis. Chest, 25, 172.

Petermann, Mary L., Hamilton, Mary G., and Reilly, H. Christine (1952). Arch. Biochem., $37,117$.

Rankin, N. E. (1953). Brit. med. J., 1, 918.

Rénon, L. (1897). Étude sur L'Aspergillose chez Les Animaux et chez L'Homme. Masson, Paris.

Riddell, R. W. (1958). Proc. roy. Soc. Med., 51, 491.

Segretain, G. (1958). In Fungous Diseases and Their Treatment, p. 128 , ed. R. W. Riddell and G. T. Stewart. Butterworth, London.

Seligman, E. (1953). Proc. Soc. exp. Biol. (N.Y.), 83, 778.

Sidransky, H., and Friedman, L. (1958). Amer. J. Path., 34, 585.

(1959). Ibid., 35, 169.

Soltys, M. A. (1944). Nature (Lond.), 154, 550.

Stefanini M. Adamis, D. M. Soardi, F., Horace, J. F., Marin, H. M., and Mele, Rose (1959). Lancet, $2,443$.

Symmers, W. St. C. (1958). In Fungous Diseases and Their Treatment, p. 25 , ed. R. W. Riddell and G. T. Stewart. Butterworth, London.

Thom, C., and Raper, K. B. (1945). A Manual of the Aspergilli. Williams and Wilkins, Baltimore.

Tomaszewski, T. (1951). Brit. med. J., 1, 388.

Torack, R. M. (1957). Amer. J. Med., 22, 872.

Torre, C. M., and Leikin, S. L. (1959)., Amer. J. clin. Path., 32, 335.

Welsh, R. A., and McClinton, L. T. (1954). A.M.A. Arch. Path., 57, 379.

Wybel, R. E. (1952). Ibid., 53, 167.

Zimmerman, L. E. (1955). Amer. J. clin. Path., 25, 46. 